\title{
La Crema: A Case Study of Mutual Fire Insurance
}

\section{Antonio Cabrales}

Universitat Pompeu Fabra

Antoni Calvó-Armengol

Universitat Autònoma de Barcelona

Matthew O. Jackson

California Institute of Technology

\begin{abstract}
We analyze a mutual fire insurance mechanism used in Andorra, which is called La Crema in the local language. This mechanism relies on households' announced property values to determine how much a household is reimbursed in the case of a fire and how payments are apportioned among other households. The only Pareto-efficient allocation reachable through the mechanism requires that all households honestly report the true value of their property. However, such honest reporting is not an equilibrium except in the extreme case in which the property values are identical for all households. Nevertheless, as the size of the society becomes large, the benefits from deviating from truthful reporting vanish, and all the nondegenerate equi-
\end{abstract}

We are grateful to Francisco Alcalá, Luis Corchón, Ashok Rai, Massimo Motta, Rafael Repullo, Joel Sobel, and the seminar participants at the European Winter Workshop of the Econometric Society and the University of California, Irvine Development Economics Conference for their comments. We thank Pierre-André Chiappori and an anonymous referee for helpful suggestions. We also gratefully acknowledge the financial support of Spain's Ministry of Education under grants BEC2000-1029 and SEC2001-0973, the Generalitat de Catalunya under grant 1999SGR-00157, and the National Science Foundation under grant SES-9986190. Finally, special thanks to Benito Marquet Armengol, Cal Ton de Borró, for help with details regarding the history and operation of La Crema and for access to the data. This paper was written while Calvó-Armengol was at Universidad Carlos III.

[Journal of Political Economy, 2003, vol. 111, no. 2]

(C) 2003 by The University of Chicago. All rights reserved. 0022-3808/2003/11102-0002\$10.00 
libria of the mechanism are nearly truthful and approximately Pareto efficient.

\section{Introduction}

Mutual insurance companies write a large fraction of insurance policies in many sectors. ${ }^{1}$ They have been very successful for several reasons. First, as Malinvaud (1973, p. 398) points out, future markets provide only a remote idealization to the actual mechanism for risk allocation since "the ideal market system is too costly to implement." On the contrary, pooling individual risk by means of mutual insurance policies "permits substantial economizing on market transactions" (Cass, Chichilnisky, and Wu 1996, p. 335). Another important reason for the success of mutual insurance is that through peer monitoring it can solve some moral hazard problems that plague incorporated insurance companies. ${ }^{2}$ While these problems are well understood, mutual insurance arrangements also solve other informational problems relating to the discovery of the value of insured property, as we show here.

In this paper we present and analyze a real-life mutual fire insurance mechanism that has been functioning for over a century and a half in Andorra, a small principality in the Pyrenees, a rural mountainous area of western Europe. In this mechanism, called La Crema in the local language, each participating household must report a value. In case there is a fire, the owner of the burned household receives her reported value, which is paid by all participating households (including herself) in proportion to their reported values. We focus on the rules of $L a$ Crema because they are particularly clear from a game-theoretic point of view, they are by no means exceptional, and the mechanism has some remarkable properties. ${ }^{3}$

\footnotetext{
${ }^{1}$ Williams, Smith, and Young (1997, p. 398) state that "advance premium mutuals write almost 40 percent of the life insurance in force and almost 23 percent of the property and liability insurance premiums."

${ }^{2}$ According to Heimer (1985, p. 64), "Mutuals seem to have been more effective than stock companies in constructing such incentive systems, particularly in the early phases of their history. Individual industrialists were sometimes large enough to make investment in research on fire prevention worthwhile, but stock companies discouraged the provision of public goods by appropriating too much of the saving from decreased fire losses." Obviously, mutuals have problems of their own, or they would be the only organizational form. Garber (1993, p. 8) writes that "from a financial perspective, the key impediment to mutual life company stability, growth and development, is that equity capital can be raised only through retained earnings from the company's operations." Also, mutuals are very difficult to take over, which makes the corporate governance problem harder to solve, especially in large mutuals.

${ }^{3}$ The term "mutual insurance" (often "mutual" for short) covers a variety of insurance systems. Mutuals are generally corporations owned by their policyholders and are structured for their benefit. There are two main types of mutuals. "Advance premium mutuals"
} 
In particular, the properties of the La Crema mechanism that we explore concern its efficiency characteristics and the incentives it provides for truthful reporting of property values. One important characteristic is that the mechanism allows for announcement of any value by households and does not seek any appraisal or cross report by any witnesses. Moreover, as we discuss below, all that needs to be verified is that the property burned, and then the announced value is reimbursed. This is potentially a nice feature because it allows the mechanism to insure the "subjective" value of property (as a welfarist would like) rather than the appraisable market value. The subjective value can include sentimental factors that could not be valued appropriately by the market. This additional feature of the mechanism will be useful only if the mechanism provides incentives to (approximately) announce truthfully and provides for efficient risk sharing. We shall see that, under appropriate conditions, the mechanism performs these tasks quite well, and without having to resort to audits or other forms of "independent" assessments.

Let us now discuss the mechanism's performance in more detail.

With regard to efficiency, the mechanism places strong constraints on the possible risk sharing that can take place since reimbursements and payments are both scaled directly in terms of the announced property values. For instance, if households have constant (and identical) relative risk aversion, the only Pareto-efficient allocation that is reachable through the game requires that all households truthfully report the value of their property. Things are even worse with constant (and identical) absolute risk aversion since then no Pareto-efficient allocation is obtainable as an outcome in the game regardless of how the announcements are varied. ${ }^{4}$

With regard to the incentives that the mechanism provides for truthful reporting of property values, we show that there is an equilibrium in which all households report the true value of their insured property if and only if these valuations are exactly the same across households. Apart from this extreme case of identical property values, we show that

set premiums at a rate that is expected to cover expenses and expected losses and build up a fund for contingencies. "Assessment mutuals" differ from advance premium mutuals in that they have a right to assess the policyholders (i.e., collect money after a loss). Technically La Crema is an assessment mutual, in particular, one that is entirely based on assessments after a loss, but in which those assessments are based on valuations that are reported in advance. It is important to note that the rules of this mutual insurance system are not unique to La Crema. A similar proportional assessment rule is adopted, for instance, in marine insurance clubs: "At the beginning of the year the shipowners are given an estimate of the amount (call) they will be required to pay into the [Protection and Indemnity] Club. However, the eventual call is dependent upon the claim made by all members: each member knows only the proportion of the total cost they will be required to bear" (Bennett 2000, p. 152; emphasis in the original).

${ }^{4}$ As one would expect, by the nature of the mechanism, where only property values are reported, differences in risk aversion do not seem to be the answer either. 
households with relatively high property values have an incentive to overreport their value (to increase reimbursement from others when needed) and households with low property values have an incentive to underreport their value (to decrease payment to others when asked for).

The analysis described above appears to be in conflict with the conventional wisdom among the actual participants in the game, who are happy with the functioning of the mechanism and consider that the only natural thing one can do is to report the true value of the property. Since the mechanism has existed for a long time, one would think that tradition or their own experience could furnish enough information for agents to know their best response. In fact, the incentive and efficiency properties that the mechanism exhibits are quite appealing and are closely in line with local wisdom once we examine large enough societies and consider approximate rather than exact efficiency.

From the perspective of larger societies, we first show that households in large enough societies have arbitrarily small incentives to deviate from honest reporting, or, in other words, truth is an $\epsilon$-Nash equilibrium. Second, we show that in large enough societies, the (exact) Nash equilibria of the La Crema mechanism involve reports that are arbitrarily close to the truth. ${ }^{5}$ Third, the Nash equilibria (and $\epsilon$-Nash equilibria) are arbitrarily close to being Pareto efficient in large enough societies. Finally, we show that, for reasonable parameterizations of utility functions, what is needed in the statements above in terms of "large enough" societies can actually be reasonably small. Moreover, these results are robust to variations in the informational structure since they hold both with complete and with private information.

The interest of this institution is manifold and quite different from other studies of risk-sharing institutions. ${ }^{6}$ First of all, the La Crema institution refers to a specialized type of risk, which allows us to model it relatively simply and yet still accurately and also limits the potential explanations for the behavior of participants. Second, the transfer rules are quite explicit and are easily modeled. Finally, the rural society under consideration is relatively stable during the whole period of the mech-

\footnotetext{
${ }^{5}$ One should note, of course, that while the larger scale of society may solve the reporting problem of La Crema, it may create other problems since providing adequate fire prevention can become now a worse public-good problem. "Today's P\&I [Protection and Indemnity] Clubs are global in scale, with the largest containing over 20 percent of the world's oceangoing fleet. Communal responsibility may be unrealistic in such large-scale institutions because free rider problems become more difficult to monitor and control as group size and dispersion increase" (Bennett 2000, p. 148).

${ }^{6}$ Such as the ones mentioned in McCloskey (1989), Townsend (1993), or Fafchamps (1999). Besley, Coate, and Loury $(1993,1994)$ examine the allocative performance of a simple, easily organized, and widely observed institution for financial intermediation called rosca (rotating savings and credit associations).
} 
anism's operation (e.g., there are no instances of famines during its existence), and so wealth constraints are not an issue.

Before we move on, let us remark on the comparison of the La Crema institution to a competitive insurance market. First, as discussed above, the equilibrium outcomes accounting for incentives will result in approximately efficient outcomes, and so the mechanism is not dominated in any strong way by a competitive market. Second, as mentioned above and discussed in more detail below, the mechanism allows for insurance of the subjective value of property and requires only the verification that a building burned and does not require any assessment of the value of the building. Third, as discussed below, the mutual mechanism in a tight-knit society provides incentives for some peer monitoring that can help eliminate the moral hazard problem of arson. Fourth, under $L a$ Crema, no transfers or payments are made in the absence of damages, which is in contrast to most all other mechanisms for insurance. ${ }^{7}$ This item might actually go a long way toward explaining the use of La Crema. This society was, at the time of inception, relatively poor and physically isolated a large part of the year, so transferring income across periods or to and from outlying individuals was costly and difficult. ${ }^{8}$ This isolation could produce transactions costs that make operation of a competitive insurance market prohibitively costly. This, coupled with the relatively low incidence of fires (just 21 between 1884 and 1950, as documented in App. table B1) and the nice approximate efficiency properties of La Crema, makes mutual insurance a sensible institutional arrangement and the absence of transfers in the absence of fire technologically expedient.

The remainder of the paper proceeds as follows. Section II describes the mechanism (informally and formally) and gives some background on the society in which the institution operates. Section III discusses the equilibrium and efficiency properties of the mechanism. Section IV provides results characterizing the equilibria and approximate efficiency of the mechanism in "large" societies. Section V presents conclusions.

\footnotetext{
${ }^{7}$ It can be shown, for instance, that if individuals have constant relative risk aversion (CRRA) preferences, then the truthful reporting outcome of La Crema is the only allocation that is Pareto efficient under the requirement that there are no transfers in the absence of burnings.

8 "Andorra is a poor country which has often experienced scarcity" (Brutails [1904] 1965 , p. 11; translated from French by the authors). The title of a subsection of Brutails' book (p. 15) also reflects the geographical isolation of the country: Relative Isolation: The Roads. A historical account of social and economic life in nineteenth-century Andorra can be found in López Muntanya, Peruga Guerrero, and Tudel Fillat (1988), who document the many forms of cooperative life set up in the country to cope with economic precariousness: "the economic difficulties of the country made the Andorrans, already on the eighteenth century, form associations, with the goal of providing mutual assistance in case of sickness, death, and so on" (p. 147; translated from Catalan by the authors).
} 
Appendix A contains the proofs, and tables in Appendix B provide some data from the institution.

\section{La Crema}

\section{A. The Institution of La Crema}

In 1882, and under the initiative of the local priest, the 102 farms of Canillo in the Principality of Andorra ${ }^{9}$ organized themselves into a fire insurance cooperative named La Crema. By that time, Andorra was mostly a rural area living in quasi autarchy, and La Crema was conceived as a risk-sharing institution to cope with fire damages that were a source of major worries to farmers in mountainous Canillo, where sinuous and steep roads did not allow for quick or effective fire brigades. Since its early beginnings, La Crema had two roles: as a logistic structure, to organize the local firefighter forces; and as a financial structure, to guarantee pecuniary compensations to farms suffering destruction by fire. ${ }^{10}$

La Crema is organized as follows. Once a year, the cooperative members meet in a general assembly, the consell de La Crema (La Crema council). The meeting is fixed on the Sunday that falls two weeks before the carnival, and attendance is compulsory for all members. ${ }^{11}$ The meeting is supervised by two permanent secretaris (secretaries), who are elected for life. During this general assembly, each farmer announces a value for each of the buildings that he or she owns (farm, barn, cowshed, stable, etc.). Conventional wisdom suggests that farmers report the true and total value of their property, and La Crema cooperative members typically do so. This amount is noted in three different books: each secretari keeps a copy at home, and a third book is stored at the

\footnotetext{
${ }^{9}$ The Principality of Andorra, located in the heart of the Pyrenees between France and Spain, is one of both the smallest and the oldest states in western Europe: the national territory is 468 square kilometers, and today's frontiers were definitely settled in 1278 . The country is divided administratively into seven parishes: Canillo, Ordino, La Massana, Encamp, Andorra la Vella, Sant Julià de Lòria, and Escaldes-Engordany. Agriculture had been the major economic activity of Andorra until the end of the nineteenth century; tourism, commerce and financial services are now the basic national economic activities. In 1999, the gross domestic product per capita was U.S.\$20,252. See http:// www.turisme.ad/angles/ for more details.

${ }^{10} \mathrm{La}$ Crema is still active and intervened recently to financially compensate Cal Soldevila, whose barn burned in August 1998, and Cal Batista for similar damages in July 1985.

${ }^{11}$ An absent member without a good excuse is fined. The last fine dates back to 1946 .
} 
parish town hall. ${ }^{12}$ In the case of a fire, the owner of the damaged building receives compensation equal at most to the value noted in the book for the current year, depending on the extent of the damages. This financial compensation is made by the other cooperative members, who pay in proportion to the share their own announced property value represents with respect to the total of all values announced by La Crema members. The existing evidence indicates that La Crema-announced valuations are not used for any transactions (e.g., real estate transactions or taxation) outside of the La Crema mutual insurance mechanism. ${ }^{13}$ An early reference and brief description of the La Crema transfer rule can also be found in Brutails ([1904] 1965, p. 42):

As it is often the case with societies living in inhospitable areas, solidarity is highly developed among the Andorrans, and has given rise in particular to mutual fire-insurance associations. Inhabitants of a same village can usually all become insurance society fellows. Nonetheless, buildings offering fire-risks above average may be denied insurance coverage. In case of damage, all fellows pay to compensate the owner for her loss, and they do so in proportion to the value for which they are themselves insured. [Translated from French by the authors] ${ }^{14}$

During the yearly meeting, four comissionats (commissioners) and

\footnotetext{
${ }^{12}$ Details regarding the history and operation of La Crema as well as data on past transactions have been obtained from different sources. First, conversations with locals provided thorough information about the functioning of the institution. We are particularly indebted to one secretari, Josep Torres Babot, Cal Jep, and to the Canillo public librarian, $\mathrm{M}^{\mathrm{a}}$ Dolors Calvó Casal, Cal Soldevila, for long, valuable discussions. Second, bibliographic sources added a historical perspective (Brutails 1904; López Muntanya et al. 1988). Finally, the second secretari, Benito Marquet Armengol, Cal Ton de Borró, gave us access to his copy of the La Crema book. This book, as well as two other copies of it, contains data on announced values and past damages (see App. tables B1 and B2), the minutes of the yearly councils, and the standing rules of the insurance cooperative (which we discuss in detail and quote from in what follows).

${ }^{13}$ This evidence comes, first of all, from our discussions with the secretaris. In addition, one should note that Andorra has only indirect taxation, so no assessment of personal income or wealth is needed for fiscal purposes. As for real estate transactions, they were virtually absent until the 1960s. A reason for this can be found in the ethnographic study of Comas d'Argemir and Pujadas (1997). They show that Andorra has a troncal family system, which is based on the uninterrupted succession of generations living in the same house. Also, the inheritance law of Andorra (based on Roman civil law) provides that only the older child of a family inherits the undivided agricultural property. In this way, the family farm remains a whole.

${ }^{14}$ López Muntanya et al. (1988) also state that for the mutual fire insurance association of Ordino (another municipality), "the damages will be paid, among all the members of the association, in proportion to the value that each one has declared for his own property" (p. 150; translated from Catalan by the authors). The municipality of Massana has a mutual fire insurance association, and the rules for payment and reimbursement are like those of Ordino, according to López Muntanya et al.
} 
three recaudadors (money collectors) are elected for one year. The comissionats are responsible for the logistic and technical activities. First, they guarantee that all cooperative members take the appropriate precautionary measures to prevent possible fires by reporting to the consell de La Crema carelessness in farm and building maintenance and to report any problematic behavior. Second, they are in charge of the fire-fighting material owned by the cooperative (fire hoses etc.). Finally, in case of fire, the comissionats fix, in accordance with the concerned farmer, the total value of the damages to be reimbursed (depending on the extent of the damages and not exceeding the value noted in the book) and submit it to the consell for approval. The three elected recaudadors each represent a different geographical area: Canillo, la Ribera, and Prats. ${ }^{15}$ In case of fire, and once the amount to be transferred to the damaged farm is fixed by the consell under proposition of the comissionats, the recaudadors are responsible for collecting the contributions of the $L a$ Crema members within their area of intervention.

We emphasize one aspect of the reimbursement. The way in which the comissionats assess the value of damages is quite simple, and little needs to be verifiable. When reporting the value of a farm, a family can subdivide the value into values associated with separate buildings (house, barn, stable, woodshed, mill, etc.; see App. table B2). When a building or more is destroyed, the comissionat's only role is to verify that indeed the building(s) did burn. ${ }^{16}$ There is no attempt (or need) to assess the actual value of the property destroyed. As stated in Article 2 of La Crema, "in case of a loss, the announced value and no more than that will be reimbursed"; that is, the farmer receives reimbursement for the value he or she originally reported. As we shall argue, that (subjective) value will be approximately truthfully announced in equilibrium. Thus the only thing that needs to be verified is that the property burned.

In the formal game-theoretic analysis, we focus on the incentives to report truthfully the value of the property. As we mention in the Introduction, the relevant valuation here is the individual subjective value, which may be very different from the market valuation. Because of this, there is quite a lot of freedom in the mechanism for reporting valuations. Unfortunately, this implies that there may be incentives to overinsure one's property and then burn it. If players could commit arson (and not be caught), that would destroy the possibility of insurance ( La Crema or otherwise), which is why commercial firms typically disallow insuring

${ }^{15}$ The first region, Canillo, corresponds to the main town with the same name. The second region, la Ribera, includes the following villages: Els Plans, Els Vilars, El Tarter, L'Aldosa, L'Armiana, Ransol, and Soldeu. Finally, the last region, Prats, includes El Forn, Meritxell, Molleres, and Prats.

${ }^{16}$ Partial burning of a building is extremely unlikely given the harsh terrain, wood construction, and limited fire-fighting capabilities. 
a property above its market price. There are two deterrents to arson under La Crema. First, as under other insurance arrangements, there is a chance of being caught and suffering severe penalties (long prison terms). Second, La Crema, being a mutual insurance arrangement in a tightly knit society, adds another dimension that a commercial or market-based insurance scheme would not: given that each household is insured by its neighbors, the neighbors have an added incentive to monitor the behavior of a given household to make sure that it abides by the fire codes and does not commit arson. ${ }^{17}$

\section{B. The La Crema Game}

There is a set $N$ of households, with $|N|=n$. Each household has a utility function $u_{i}$ and wealth $w_{i} \in[c, C]$, where $C \geq c>0$. Let $W=$ $\sum_{i \in N} w_{i}$. We take each $u_{i}$ to be twice continuously differentiable and strictly concave.

The previous paragraph expresses the central simplifying assumption we make in modeling the game: we treat wealth as the property that may potentially burn. Utility functions may, of course, be normalized so that this assumption is made without loss of generality. But we are ignoring the subdivision of properties into separate insurable units (as discussed above, e.g., house, barn, stables, etc.), which is done in practice as seen in Appendix table B2. Adding the consideration of such subdivisions is a relatively straightforward extension, but at the expense of considerable complication in notation and exposition. ${ }^{18}$

Let $S=2^{N}$ be the set of possible states. In particular, $s \in S$ is a list of farms that burned. For instance, $s=\{2,7,12\}$ denotes that farms 2 , 7 , and 12 (and only those farms) burned. Let $S^{(k)}=\{s|| s \mid=k\}$ be the set of states in which exactly $k$ farms burn. Note that $S=\cup_{k=0}^{n} S^{(k)}$. For any $i \in N$, let $S_{i}$ denote the set of states for which farm $i$ burns (perhaps along with some other farms) and $S_{i}^{(k)}$ be the set of states for which $k$ farms in addition to farm $i$ burn. Let $p_{s}$ be the probability of state $s$. We assume that all states in which an identical number $k$ of farms burn are equally likely. That is, for all $s, s^{\prime} \in S^{(k)}, p_{s}=p_{s^{\prime}}$, and we denote this

\footnotetext{
${ }^{17}$ Article 11 of La Crema states that "any mutualist who is known to go about with wooden torches, or the damage is known in any way to be due to carelessness, will not be reimbursed for damages by the mutual." In the same vein, a new article (number 21 dated 1928) deals with electric wiring and conditions it must meet.

${ }^{18}$ When subdivided properties are used, the calculations are still close to those we have. In particular, the calculations separate so that it is (almost) as though the subdivisions of a property were separate households. The main restriction that we must still maintain is the assumption on probabilities $\left(p_{k}\right)$ as described below, where now $k$ becomes the total number of subdivisions that burn. This still allows for the possibility of some correlation but does impose restrictions.
} 
probability by $p_{k}{ }^{19} \mathrm{~A}$ special case of this is one in which each farm burns with an independent and identical probability. Note, however, that it is not required that the burnings be independent. As an extreme example, it could be that $p_{0}>0, p_{n}>0$, and $p_{k}=0$ for all other $k$. This might be an example in which all the farms lie close to each other in a forest, so that either all farms burn or none burns. All we assume is that $p_{k}>0$ for some $k>0$, so that there is some chance of a fire.

We now describe formally the rules of the La Crema game. Each household sends a message $m_{i} \in[0,2 C]$ to the coordinator, which is interpreted to be an announcement of their (subjective) property value at risk. ${ }^{20}$ Let $\mathbf{m}=\left(m_{1}, \ldots, m_{n}\right) \in[0,2 C]^{n}$ be a vector of messages. Let $M=\sum_{i \in N} m_{i}$ and, for all $s \in S$, let $M_{s}=\sum_{i \in N \backslash s} m_{i}$. The allocation rule used by the coordinator is the following: in state $s \in S$, household $i \in$ $s$ receives $m_{i}\left(M_{s} / M\right)$, whereas each household $j \in N \backslash s$ receives $w_{j}-$ $m_{j}\left[\left(M-M_{s}\right) / M\right]$. One can easily check that

$$
\sum_{j \in N \backslash s} m_{j} \frac{M-M_{s}}{M}=\sum_{i \in s} m_{i} \frac{M_{s}}{M},
$$

namely, that the sum of the contributions by households $j \in N \backslash s$ whose farms did not burn is equal to the sum that households $i \in s$ receive as a compensation for their losses. Note that if announcements are truthful $\left(m_{i}=w_{i}\right)$, then in each state $s$ the undamaged property is effectively distributed among all households in proportion to their wealths (so the final allocations are $\left.W_{s}\left[w_{i} / W\right]\right)$.

\section{Discussion of the Game}

\section{A. Equilibria}

The first proposition says that truthful announcements are a Nash equilibrium only in the case in which all wealths are identical.

Proposition 1. The La Crema game has a Nash equilibrium in pure strategies in which $m_{i}=w_{i}$ for all $i \in N$ if and only if $w_{i}=w_{j}$, for all $i, j \in N$.

The proof of proposition 1 appears in Appendix A. The intuition behind the proposition is roughly as follows. Increasing $m_{i}$ has two effects. First, it increases the reimbursement that household $i$ receives in the case of a fire that consumes $i$ 's property. Second, it increases the

\footnotetext{
${ }^{19}$ This condition is important in the approximate efficiency and equilibrium results we obtain. If this condition does not hold, so that there are some asymmetries in relative probabilities that different farms burn, then one could form subgroups for insurance in which farms with similar probabilities were grouped together. This will become clear in the proofs of the propositions and in some discussion below.

${ }^{20}$ The upper bound on announcements is arbitrarily set at twice the highest imaginable property value. Any upper bound would do.
} 
liability that $i$ faces in the event that some other household's property burns. Some heuristic calculations help illustrate the relative size of these two effects and the incentives that households have as a result. For simplicity, consider a situation in which at most one household will have a fire, and so we need consider only states of the form $\{i\}$, where $i$, property is destroyed. ${ }^{21}$ Consider what happens if $i$ raises $m_{i}$ by some small amount $\epsilon>0$. This increases $i$ 's reimbursement by (approximately) $\epsilon\left(M_{i} / M\right)$ if the state is $\{i\}$ (recall that $M_{i}=\sum_{j \neq i} m_{j}$ and $\left.M=\sum_{j} m_{j}\right)$. It also increases the payments that $i$ has to make to household $j \neq i$ in state $\{j\}$ by $m_{j}(\epsilon / M)$. Note that when we sum across states, these cancel each other out. That is,

$$
\epsilon \frac{M_{i}}{M}=\sum_{j \neq i} m_{j} \frac{\epsilon}{M}
$$

So, by lowering the announcement $m_{i}$, household $i$ transfers wealth from state $\{i\}$ to the other states $\{j\}, j \neq i$, and vice versa from raising the announcement. So what are the households' incentives in the game? Given their risk aversion, they wish to come as close as possible to smoothing their wealth across the states. If all households have exactly the same wealth, then at a truthful announcement in the La Crema game, household $i$ gets final wealth $w_{i}\left(W_{s} / W\right)$ in state $s$ and, given the equal starting wealths, is equal across each state $s=\{k\}$. Thus the households' wealths are evenly spread across these states, and they have no incentives to change their announcements. Next, consider the case in which households do not have the same wealth. Order them so that $w_{n} \geq w_{n-1} \geq$ $\cdots \geq w_{1}$ and $w_{n}>w_{1}$. Then notice that farmer 1 consumes the highest amount in the state in which her property burns, $w_{1}\left(W_{1} / W\right)$ versus $w_{1}\left(W_{j} / W\right)$ in some state $j \neq 1$, since $W_{1} \geq W_{2} \geq \cdots \geq W_{n}$. By lowering $m_{1}$ a little, household 1 decreases consumption in the state $\{1\}$, where farm 1 burns, and distributes a commensurate increase among other states $\{j\}$, where farm $j \neq 1$ burns. As households are risk averse, this strictly benefits household 1 . Conversely, farmer $n$ consumes less in the state in which farm $n$ burns compared to states in which some other farm burns. By raising $m_{n}$, farmer $n$ shifts wealth from states $\{j\}, j \neq$ $n$, to state $\{n\}$. Roughly, households with below-average property value will benefit from underreporting, and those with above-average property value will benefit from overreporting.

The proposition tells us that the game does not have an equilibrium in which households report the true value of their property if there is

${ }^{21}$ The state in which no farm burns has no impact since no payments are made. States in which several farms burn have calculations analogous to those discussed here, since the consideration is what happens if $i$ s farm burns vs. some other farm burns (on the margin). 
any heterogeneity in household value. The case of heterogeneity is arguably the interesting case, since it would be hard to see the reason for an elaborate mechanism (which is not costless to administer) unless there were some kind of heterogeneity. Otherwise, there would be common knowledge precisely about the thing that the coordinator is trying to elucidate.

This result still holds when there is private information about property values. All that is needed (this is clear from the proof as well as in the intuition above) is for some households to be fairly sure that they have the top or bottom property value (or that they are close to either).

The following remark shows that the problem goes even further. When there are only two households, there is no interior pure-strategy equilibrium to the game at all. Either both households refuse to participate (there is always such a degenerate equilibrium in which neither household declares any wealth given the expectation that the other will not) or the wealthier household has such a strong incentive to overreport that it reports the maximum allowed property value.

Remark 1. Let $n=2$. If $w_{1}\left[1+\left(w_{2} / 4 C\right)\right]<w_{2}$ (a sufficient condition for which is $\left.w_{1}<\frac{3}{4} w_{2}\right)$, then the only pure-strategy Nash equilibria of the La Crema game are $\left(m_{1}, m_{2}\right)=\left(\begin{array}{ll}0, & 0)\end{array}\right)$ and $\left(m_{1}, m_{2}\right)=$ $\left(2 w_{1} C /\left(4 C+w_{1}\right), 2 C\right)$.

It is hard to see what an insurance mechanism is trying to accomplish if it leads to such extreme outcomes.

Before providing an answer to this paradox, let us examine the Pareto efficiency characteristics of the La Crema game.

\section{B. Efficiency}

Let $W_{s}=\sum_{i \in N} w_{i}-\sum_{i \in s} w_{i}$. Thus $W_{s}$ is the total wealth in the society given that $s$ is the state. Let a risk-sharing allocation be any random vector $\mathbf{x}=\left(x_{1}, \ldots, x_{n}\right)$ such that $\sum_{i \in N} x_{i}(s)=W_{s}$ in each state $s$. Thus a risksharing allocation is some distribution of the wealth in the society. Note that this includes risk-sharing schemes that are not available as outcomes of the La Crema game. Let $E u_{i}(\mathbf{x})$ denote the expected utility of $i \in N$ under the risk-sharing allocation $\mathbf{x}$. Let $x^{m}$ denote the risk-sharing allocation that comes from announcements $m$ in the La Crema game, and let $x^{w}$ denote the risk-sharing allocation that comes from truthful announcements $\left(m_{i}=w_{i}\right)$ in the La Crema game.

We begin with efficiency results for the special case in which households have identical CRRA utility functions (i.e., $u_{i}\left(c_{i}\right)=c_{i}^{\gamma} / \gamma$ with $\gamma \neq 1$ ). We show that even in this special case the only Pareto-efficient ${ }^{22}$

${ }^{22}$ Pareto efficiency is, of course, relative to the expected utilities for an allocation. Thus expectations are taken before the state is realized, and so households do not know which property has been destroyed. 
allocations that can be reached as outcomes of the La Crema game arise from reporting the true value of one's household. The reason is that equality of marginal rates of substitution across states of the world requires that ratios of consumption are equalized for all states of the world. This can happen only when households report the true value of the property.

Proposition 2. If households have identical CRRA utility functions and there exist $i, j \in N$ such that $w_{i} \neq w_{j}$, then there is a unique Paretoefficient risk-sharing allocation that is reachable through the La Crema game. It is to have each household report truthfully. So $x_{i}^{w}(s)=$ $w_{i}\left(W_{s} / W\right)$ for all $i \in N$, for all $s \in S$.

We note that propositions 1 and 2 imply that the only Pareto-efficient outcome of the La Crema game (under identical CRRA) cannot be sustained as a Nash equilibrium.

Given that (Arrow-Debreu complete market) Walrasian outcomes are efficient, an interesting question in this context is whether the unique Pareto-efficient outcome reachable through the La Crema game (when households have identical CRRA utility functions) corresponds to the Arrow-Debreu complete market Walrasian equilibrium of this economy when the endowments for the household $i$ are $w_{i}$ in state $s \notin S_{i}$ and zero in states $S_{i}$. The following remark shows that this is generically not the case.

REMARK 2. Let the probability that any farm burns be given by $p>$ 0 and have this probability be independent across farms. If there exist $k$ and $j$ such that $w_{k} \neq w_{j}$, then the unique Pareto-efficient allocation reachable through the La Crema game when the players have identical CRRA utility functions is different from the outcome of the complete market Walrasian equilibrium of the La Crema economy.

The next proposition shows that if agents have constant absolute risk aversion (CARA) utility functions, then difficulties in reaching efficiency are even worse for the La Crema game in that all the allocations that are reachable through the game are inefficient. The reason is that Pareto optimality with identical CARA utility functions requires that differences in utilities across states of the world are equalized across agents. This demands on the one hand that reports are the same for all agents and at the same time that they are truthful. With heterogeneous endowments, the two requirements are not compatible.

Proposition 3. If, for some $i, j \in N, w_{i} \neq w_{j}$ and households have identical CARA utility functions, then there is no Pareto-efficient allocation that can be reached through the La Crema game.

The following remark shows that differences in risk attitudes across households will not help to explain the inefficiency of the La Crema game. This is evident when the probability that no property burns is different from zero $\left(p_{0}>0\right)$ because in that case Pareto efficiency re- 
quires transfers from the relatively more risk averse agents to the relatively less risk averse agents when no property burns (i.e., in state $s \in S^{(0)}$ ), and La Crema specifies no transfers for $s \in S^{(0)}$. The remark shows that even if there were some household burning in all states of the world $\left(p_{0}=0\right)$, there would still be no Pareto-efficient outcome of the game.

Remark 3. Assume that $n \geq 3$, household $i=1$ is risk neutral, the other households have (possibly heterogeneous) CRRA utility functions, and, for some $i, j \in N, w_{i} \neq w_{i}$; then there is no Pareto-efficient allocation that is obtainable through the La Crema game.

The results above leave us with a puzzle that needs to be explained. Pareto efficiency can be obtained only through the La Crema game in some extreme cases, and even then the corresponding allocation cannot be sustained as an equilibrium of this game as long as there is any heterogeneity in household property values. So why would the La Crema game be used? An analysis of larger societies provides an answer.

\section{Larger Societies}

While proposition 1 shows that truth is a Nash equilibrium only in extreme (and implausible) situations, the La Crema game still has very nice features in terms of its equilibrium structure and efficiency characteristics. We point these out in a series of propositions. First, we show that truth is an $\epsilon$-Nash equilibrium for large enough societies. Thus the gains from over- or understating one's wealth are not large. While this suggests that the La Crema game will have nice properties, it is not completely convincing since it does not guarantee that the exact Nash equilibria will be close to truthful. Second, we show that there always exist (nondegenerate) Nash equilibria. Third, we show that all nondegenerate Nash equilibria are close to truthful in large societies. Thus the La Crema game provides incentives for individuals to play (approximately) truthfully. Finally, we show that truth and all announcements close to the truth are approximately Pareto efficient (with arbitrary utility functions). Taken together, these results show that the Nash equilibria and $\epsilon$-Nash equilibria of the La Crema game are approximately efficient in large societies with arbitrary heterogeneity in preferences and endowments.

In order to talk about large societies and approximation, we consider the following setting. Let $n^{1}, n^{2}, n^{3}, \ldots$ be an increasing sequence of integers such that $n^{h} \rightarrow \infty$. Each $h \in \mathbb{N}$ defines a La Crema game with population $N^{h}$ of size $n^{h}$.

In addition, we maintain the following assumption on preferences in what follows for all $i \in N^{h}$ and for all $h \in \mathbb{N}$. 
Assumption 1. For any $\mu>0$, there exists $\delta>0$ such that, if $\mid w-$ $w_{i} \mid<\delta$, then $\left|u_{i}^{\prime}(w)-u_{i}^{\prime}\left(w_{i}\right)\right|<\mu$.

Assumption 1 implies that the second derivative of utility functions has some bound that applies to all players and games. ${ }^{23}$ In other words, players are not arbitrarily risk averse. Note that no particular form is assumed for the utility functions $u_{i}$, so they can differ across people as long as there is an upper bound on how risk averse people are.

\section{A. Approximate Equilibria}

Proposition 4. For any $\epsilon>0$, there exists an integer $H$ such that, for any $h>H$, it is an $\epsilon$-Nash equilibrium of the La Crema game for all people in $N^{h}$ to report truthfully $\left(m_{i}=w_{i}\right)$.

The proof of proposition 4 appears in Appendix A. To get a feeling for the intuition, let us do the following exercise. Changes of a given $m_{i}$ have relatively little impact on $M=\sum_{i} m_{i}$ in a large society, so let us treat $M$ as fixed since the effects on it are second-order (these effects are carefully handled in App. A). Consider a scenario in which one farm burns, but we are not sure which. So the conditional expectation is $1 / n$ on each farm. What happens if household $i$ increases $m_{i}$ by one unit? The gain is roughly

$$
\frac{1}{n} \sum_{j \neq i} \frac{m_{j}}{M} u_{i}^{\prime}\left(m_{i}-\frac{m_{i}^{2}}{M}\right)
$$

in the case in which it is $i$ s farm that burns. The loss is

$$
\frac{1}{n} \sum_{j \neq i} \frac{1}{M} m_{j} u_{i}^{\prime}\left(w_{i}-\frac{m_{i} m_{j}}{M}\right)
$$

as we sum over the cases in which each other farm burns, since $i$ is liable for an extra $1 / M$ of each value $m_{j}$. Since in a large society $m_{i} / M \simeq 0$, these approximately cancel at $m_{i}=w_{i}$, and so $i$ does not gain much by changing $m_{i}$. So under the La Crema game, the expected cost (in utils) of the insurance is approximately $\sum_{j \neq i} m_{j} / M u_{i}^{\prime}\left(w_{i}\right)$, and it pays off approximately $\sum_{j \neq i} m_{j} / M u_{i}^{\prime}\left(m_{i}\right) .{ }^{24}$

Another way to view this is to go back to the intuition discussed after proposition 1. Lowering household $i$ 's announcement effectively transfers wealth from states in which $i$, s property burns to states in which

\footnotetext{
${ }^{23}$ Note that this assumption holds trivially in the CRRA case as long as $\gamma$ is bounded from above.

${ }^{24}$ When we have more than two farms burning at a time, the argument becomes a bit more complicated, but we can still match up positive and negative terms. The marginal utilities with $m_{i}-\left(m_{i}^{2} / M\right)$ and $w_{i}-\left(m_{i} m_{i} / M\right)$ are replaced, respectively, by marginal utilities of something like $m_{i}-\left[m_{i}\left(m_{i}+M_{s}\right) / M\right]$ and $w_{i}-\left[m_{i}\left(m_{j}+M_{s}\right) / M\right]$. Again, since $m_{i} / M \approx$ 0 , these terms equalize approximately when $w_{i}=m_{i}$.
} 
some other property burns in $i$ 's place. The relative difference in $i$ 's wealth across these states under truthful reporting is negligible to begin with: $w_{i}\left(W_{s} / W\right)$ is almost the same as $w_{i}\left(W_{s^{\prime}} / W\right)$ if $s$ is a state in which $i$ burns and $s^{\prime}$ is a corresponding state in which some other farm burns in $i$ 's place, since $W_{s} / W$ is almost the same as $W_{s} / W$ in a large society.

The intuition above shows that La Crema is a subtle institution since the cost of insurance depends on $u_{i}^{\prime}\left(w_{i}\right)$ and its payoff depends on $u_{i}^{\prime}\left(m_{i}\right)$ and, most important, in a way that gives agents just the right incentives (in large economies in which $M$ is approximately unaffected by $i$ s announcement).

Let us stress an important feature of the result in proposition 4 . The bounds we use in the proof are robust to the information structure and the actions of the other agents. That is, they do not depend on the $p_{k}$ 's, what the $w_{j}$ 's are for $j \neq i$, and work uniformly across $i$ 's as long as assumption 1 is satisfied. ${ }^{25}$ In fact, all that is needed is that a household believes that its property value will be a relatively small amount of the total announced property value to have truth be nearly a best response. This robustness is important not just for realism's sake. In an environment with complete information, there are formal mechanisms that implement "exactly" the efficient outcome, but this is not the case with incomplete information.

EXAMPLE 1. There is a population of 100 households that each have the same preferences, $u_{i}\left(c_{i}\right)=\sqrt{c}_{i}$. The households differ in the value of their properties: half are of a "low" type with $w_{L}=10,000$, and the other half are of a "high" type with $w_{H}=30,000$. Let the probability that a fire burns a given property be $1 / 100$ and be such that exactly one house burns. ${ }^{26}$ This allows for easy calculations and is not much different from the independently and identically distributed case in terms of incentives and expected utilities. In this case, if other households are reporting truthfully, then a low type's best response is approximately $m_{i}=9,925$, and the gain in expected utility of announcing 9,925 compared to 10,000 is approximately $10^{-5}$ out of an expected utility of approximately 99.5 , which is a gain of about only $10^{-5}$ percent. To put this in perspective, not participating leads to an expected utility of 99, and so the overall benefit of participating in La Crema is about 0.5 . Thus the gain of an optimal deviation from truth is very small even compared to the overall benefit from participation $\left(10^{-5} / 0.5\right)$. Similar

\footnotetext{
${ }^{25}$ The proof uses the fact that $p_{s}$ 's are equal across $s$ 's of the same size. We are not sure how the mechanism performs if there are drastic disparities in the probability of fires across properties. Regardless, La Crema could be made to work in such cases by separating properties into relatively homogeneous risk categories operating the mechanism separately over different risk categories, especially since much of the benefits can still be realized with relatively small numbers.

${ }^{26}$ So $p_{1}=1 / 100$ and $p_{k}=0$ for $k \neq 1$; recall that $p_{k}$ is the probability of each state in which exactly $k$ farms burn.
} 
TABLE 1

$u_{i}\left(c_{i}\right)=c_{i}^{5}$

\begin{tabular}{|c|c|c|c|c|c|}
\hline & \multicolumn{3}{|c|}{$E u_{i}$} & \multirow{2}{*}{$\begin{array}{c}\text { GAIN } \\
\text { Best } \\
\text { RESPONSE }\end{array}$} & \multirow{2}{*}{$\begin{array}{c}\text { BEST } \\
\text { RESPONSE }\end{array}$} \\
\hline & Autarchy & Truth & Best Response & & \\
\hline$n=2$ & 99.000 & 99.370 & 99.420 & .050 & 6,000 \\
\hline$n=4$ & 99.000 & 99.452 & 99.459 & .007 & 7,992 \\
\hline$n=100$ & 99.000 & 99.500 & 99.500 & $10^{-5}$ & 9,925 \\
\hline
\end{tabular}

calculations for the high type lead to a best response (to truth by the others) of $m_{i}=30,077$ and a similar-sized gain (on the order of $10^{-5}$ ) compared to truthful announcing.

Table 1 summarizes the results with these parameters for different population sizes. The results for $u_{i}\left(c_{i}\right)=c_{i}^{9}$ and $u_{i}\left(c_{i}\right)=c_{i}^{1}$ are given in tables 2 and 3, respectively. For more risk averse $u_{i}$ than the ones we give, the differences between truth and best response are even smaller. Notice that the usual estimated values for the Arrow-Pratt risk aversion parameter are between -1 and -4 (see Szpiro [1986], Barsky et al. [1997], or Chou, Engle, and Kane [1992] and references therein).

\section{B. Equilibria}

While proposition 4 is somewhat reassuring that truthful reporting of property values can reasonably be expected in the La Crema game, it leaves open the possibility that the actual equilibrium could still be quite far from truthful. (Note that generally $\epsilon$-Nash equilibria need not be near Nash equilibria.) As we now show, however, the Nash equilibria of the La Crema game are in fact close to being truthful.

Before we proceed, note that $(0, \ldots, 0)$ is always an equilibrium of the La Crema game. We call this the degenerate equilibrium. Say that an equilibrium is nondegenerate if there is some player $i$ who places probability less than one on playing $m_{i}=0$. It can be shown that any strategy in which $m_{i}<w_{i} / 2$ is weakly dominated, and so the only equilibria that do not involve weakly dominated strategies must have $m_{i} \geq w_{i} / 2$ (as is

TABLE 2

$u_{i}\left(c_{i}\right)=c_{i}^{9}$

\begin{tabular}{|c|c|c|c|c|c|}
\hline & \multicolumn{3}{|c|}{$E u_{i}$} & \multirow{2}{*}{$\begin{array}{c}\text { GAIN } \\
\text { BEST } \\
\text { RESPONSE }\end{array}$} & \multirow{2}{*}{$\begin{array}{c}\text { BEST } \\
\text { RESPONSE }\end{array}$} \\
\hline & Autarchy & Truth & Best Response & & \\
\hline$n=2$ & $3,941.3$ & $3,943.5$ & $3,944.1$ & .6 & 6,000 \\
\hline$n=4$ & $3,941.3$ & $3,944.5$ & $3,944.6$ & .1 & 8,002 \\
\hline$n=100$ & $3,941.3$ & $3,945.2$ & 345.2 & $10^{-3}$ & 9,925 \\
\hline
\end{tabular}


TABLE 3

$u_{i}\left(c_{i}\right)=c_{i}^{1}$

\begin{tabular}{|c|c|c|c|c|c|}
\hline & \multicolumn{3}{|c|}{$E u_{i}$} & \multirow{2}{*}{$\begin{array}{c}\text { GAIN } \\
\text { BEST } \\
\text { RESPONSE }\end{array}$} & \multirow{2}{*}{$\begin{array}{c}\text { Best } \\
\text { RESPONSE }\end{array}$} \\
\hline & Autarchy & Truth & Best Response & & \\
\hline$n=2$ & 2.4904 & 2.5080 & 2.5085 & .0005 & 6,000 \\
\hline$n=4$ & 2.4904 & 2.5090 & 2.5089 & .0001 & 7,982 \\
\hline$n=100$ & 2.4904 & 2.5094 & 2.5094 & $\ldots$ & 9,925 \\
\hline
\end{tabular}

shown in App. A following eq. [A8]). ${ }^{27}$ In fact, the following propositions show that nondegenerate equilibria exist and have some strong properties.

Proposition 5. There exists a nondegenerate Nash equilibrium of the La Crema game. Moreover, there exists a strict Nash equilibrium (and thus in pure and undominated strategies) in which each player $i$ plays $m_{i} \geq w_{i} / 2$ such that $4 C^{2} / W \geq\left|m_{i}-w_{i}\right|$.

The proof of proposition 5 uses the following proposition, which establishes that all nondegenerate equilibria involve players playing within certain bounds of $w_{i}$.

Proposition 6. In any nondegenerate Nash equilibrium of the $L a$ Crema game, all players place probability only on $m_{i}$ such that

$$
\frac{4 C}{W} \geq\left|\frac{m_{i}-w_{i}}{w_{i}}\right| .
$$

Thus $4 C^{2} / W \geq\left|m_{i}-w_{i}\right|$, and so as $W$ becomes large, $\left|m_{i}-w_{i}\right| \rightarrow 0$ uniformly across $i$ for any $m_{i}$ in the support of any sequence of nondegenerate Nash equilibria.

The proof of proposition 6 follows intuition similar to that behind proposition 4 . We know that the gain from misreporting is small in a large society, and the proof uses the strict concavity of $u_{i}$ to show that grossly misreporting cannot be a best response: if it involves gross underreporting, then there are substantial gains in insurance to be realized by increasing the report; if it involves gross overreporting, then the household is overexposed in its liability and benefits from decreasing the report.

Propositions 4,5 , and 6 provide a resolution to the seeming conflict between the observation that with heterogeneous societies truthful reporting is not an equilibrium of the La Crema game and the conventional wisdom among the actual participants of the game who think that it is best to report the true value of the property. These previous propositions

\footnotetext{
${ }^{27}$ In fact, $m_{i}=0$ is a best response only if all other players have $m_{j}=0$; as long there is at least one $j$ who places at least some probability on $m_{j}>0, m_{i}=w_{i} / 2$ strictly dominates any lower announcement.
} 
establish that there exist strict ${ }^{28}$ Nash equilibria that are nondegenerate and that any nondegenerate equilibrium of the mechanism is "close" to truthful reporting and gets closer the bigger the society.

\section{Approximate Efficiency}

While the results above resolve the incentive part of the paradox of the La Crema game, the efficiency characteristics are still somewhat puzzling, since in many cases fully Pareto-efficient allocations are not obtainable as an outcome of the game, even under truthful reporting. As it turns out, however, the allocation that results from truthful reporting is close to being efficient in large societies (even with heterogeneous preferences), and thus so are the outcomes associated with nondegenerate equilibria. This is formalized as follows.

Consider a sequence of economies $N^{h}$ in the La Crema game satisfying assumption 1. Normalize utility functions so that $u_{i}(0)=0$ for each $h$ and $i \in N^{h}$. Furthermore, suppose that there exists $\underline{a}>0$ and $\bar{a}>0$ such that the following assumption is true.

Assumption 2. $\bar{a}>u_{i}^{\prime}(x)>\underline{a}$ for all $x \in[0,2 C], h$, and $i \in N^{h}$.

Assumption 2 bounds the derivative of $u_{i}$ uniformly across $i$.

Proposition 7. Consider a sequence of economies $N^{h}$ in the La Crema game as described above (satisfying assumptions 1 and 2). Let the probability that any farm burns be given by $p>0$ and have this probability be independent across farms. (i) If a sequence of risk-sharing allocations $\left\{x^{h}\right\}$ Pareto-dominates $\left\{x^{w, h}\right\}$ (the allocations associated with truthful reporting in the La Crema game), then

$$
\frac{\sum_{i \in N^{h}} E u_{i}\left(x^{h}\right)-E u_{i}\left(x^{w, h}\right)}{\sum_{i \in N^{h}} E u_{i}\left(x^{w, h}\right)} \rightarrow 0 \quad \text { as } h \rightarrow \infty .
$$

(ii) If a sequence of risk-sharing allocations $\left\{x^{h}\right\}$ Pareto-dominates the allocations of the La Crema game associated with a nondegenerate Nash equilibrium $\left\{x^{m, h}\right\}$, then

$$
\frac{\sum_{i \in N^{h}} E u_{i}\left(x^{h}\right)-E u_{i}\left(x^{m, h}\right)}{\sum_{i \in N^{h}} E u_{i}\left(x^{m, h}\right)} \rightarrow 0 \quad \text { as } h \rightarrow \infty .
$$

The proof of proposition 7 uses a law of large numbers to tie down the expected property damage to the society. This means that the insurance problem can be approximated by a situation in which a given household has a good idea of the cost of insurance and faces only its

\footnotetext{
${ }^{28}$ Such equilibria are also in undominated strategies and satisfy individual rationality constraints. Note, in fact, that in the La Crema game, a player by announcing $m_{i}=0$ effectively does not participate, and so any equilibrium must satisfy an interim individual rationality constraint, and here it is satisfied strictly.
} 
idiosyncratic risk of loss of property. In such a situation, truthful announcements lead to approximately efficient outcomes, and so nondegenerate equilibria (which are approximately truthful) are also approximately efficient.

\section{Conclusions}

We have shown that true reporting leads to the unique Pareto-efficient outcome of the La Crema game, but the corresponding allocation cannot be sustained as an exact equilibrium of this game as long as there is some heterogeneity in household value. However, we have also shown that if the society is large enough, true reporting is "almost" optimal, and that the nondegenerate equilibria of the game lead to outcomes that are close to being Pareto efficient. It is worth remarking that this efficient solution has been attained by a contractual mechanism that is also relatively simple.

While the framework studied here is one with complete information about the valuations, these results hold even with private information. As we have shown, although truthful reporting is not an equilibrium (as long as some agents know that they are likely to have the highest or lowest wealth), in a large society, the deviations from truth telling by any household will be small as long as the household's property value is expected to be a relatively small amount of the aggregate announced property value. This robustness with respect to the information structure is important not just because it is more realistic. With complete information, there are formal mechanisms that "exactly" implement the efficient outcome; this is not the case with incomplete information, which gives further interest in the La Crema institution.

Mutual institutions with proportional payment/reimbursement rules are, as we discuss in the Introduction, a large part of the insurance business. But they occur in other markets. One is horse race betting: winning tickets earn back a fraction of total bets in proportion to how much one bets on the winning horse. That is usually referred to as "parimutuel" betting (Gulley and Scott 1989; Gabriel and Marsden 1990). National lottery systems often have this feature as well. This suggests that further exploring the mechanism may be a worthwhile enterprise.

As a final observation, we note that the outcome of the La Crema game preserves the relative level of wealth for all households. This contrasts with Young's (1998, p. 132) observation that "the most stable contractual arrangements are those that are efficient, and more or less egalitarian, given the parties' payoff opportunities." An interesting question for future research would be to explain why, of all the possible efficient allocations, the actual mechanism in use results in (something close to) 
one that preserves the wealth ranking under this class of adverse contingencies.

\section{Appendix A}

Proof of Proposition 1

Without loss of generality, assume that $w_{n} \geq \cdots \geq w_{1}$. Household $i$ s expected payoff is then

$$
E u_{i}(\mathbf{m})=\sum_{k=1}^{n} E u_{i}^{(k)}(\mathbf{m})+\left(1-\sum_{k=1}^{n} p_{k}\right) u_{i}\left(w_{i}\right)
$$

where, for all $n \geq k \geq 1$,

$$
E u_{i}^{(k)}(\mathbf{m})=p_{k}\left[\sum_{s \in S_{i}^{(k-1)}} u_{i}\left(m_{i} \frac{M_{s}}{M}\right)+\sum_{s^{\prime} \in S^{(k)} \backslash S_{i}^{(k-1)}} u_{i}\left(w_{i}-m_{i} \frac{M-M_{s^{\prime}}}{M}\right)\right]
$$

is the expected utility of household $i$ when $k$ farms burn. Fix some $n \geq k \geq 1$. Direct calculation gives

$$
\frac{\partial E u_{i}^{(k)}}{\partial m_{i}}=p_{k}\left(1-\frac{m_{i}}{M}\right) \Delta_{i}^{(k)}(\mathbf{m}),
$$

where

$$
\begin{aligned}
\Delta_{i}^{(k)}(\mathbf{m}) & =\sum_{s \in S_{i}^{(k-1)}}\left(\frac{M_{s}}{M}\right) u_{i}^{\prime}\left(m_{i} \frac{M_{s}}{M}\right)-\sum_{s^{\prime} \in S^{(k)} \backslash S_{i}^{(k-1)}} \frac{M-M_{s^{\prime}}}{M} u_{i}^{\prime}\left(w_{i}-m_{i} \frac{M-M_{s^{\prime}}}{M}\right) \\
& =\sum_{s \in S_{i}^{(k-1)}} \sum_{j \in N \mid s} \frac{m_{j}}{M} u_{i}^{\prime}\left(m_{i} \frac{M_{s}}{M}\right)-\sum_{s^{\prime} \in S^{(k)} \backslash S_{i}^{(k-1)}} \sum_{j \in s^{\prime}} \frac{m_{j}}{M} u_{i}^{\prime}\left(w_{i}-m_{i} \frac{M-M_{s^{\prime}}}{M}\right) .
\end{aligned}
$$

We have

$$
\left|S_{i}^{(k-1)}\right|=\left(\begin{array}{l}
n-1 \\
k-1
\end{array}\right)
$$

and

$$
\left|S^{(k)}\right| S_{i}^{(k-1)} \mid=\left(\begin{array}{l}
n \\
k
\end{array}\right)-\left(\begin{array}{c}
n-1 \\
k-1
\end{array}\right)=\left(\begin{array}{c}
n-1 \\
k
\end{array}\right) .
$$

Moreover, for all $s \in S_{i}^{(k-1)}$ and $s^{\prime} \in S^{(k)} \backslash S_{i}^{(k-1)},|N \backslash s|=n-k$ and $\left|s^{\prime}\right|=k$. There are thus

$$
(n-k)\left(\begin{array}{l}
n-1 \\
k-1
\end{array}\right)=\frac{(n-1) !}{(k-1) !(n-k-1) !}
$$

elements and

$$
k\left(\begin{array}{c}
n-1 \\
k
\end{array}\right)=\frac{(n-1) !}{(k-1) !(n-k-1) !}
$$

elements, respectively, on the left-hand-side term and on the right-hand-side term of $\Delta_{i}^{(k)}(\mathbf{m})$, that is, an identical number of elements for each sum. We then 
group these terms two by two in the following way. Let $s \in S_{i}^{(k-1)}$ and $j \in N \backslash s$. We can write $s=\left\{i_{1}=i, i_{2}, \ldots, i_{k}\right\}$. Let $s^{\prime}$ be obtained from $s$ by replacing $i$ with $j$, that is, $s^{\prime}=\left\{i_{1}=j, i_{2}, \ldots, i_{k}\right\}$. By construction, $s \cap s^{\prime}=\left\{i_{2}, \ldots, i_{k}\right\}$, implying that $M-M_{s^{\prime}}=M-M_{s}-m_{i}+m_{j}$. Therefore,

$$
\Delta_{i}^{(k)}(\mathbf{m})=\sum_{s \in S_{i}^{(k-1)}} \sum_{j \in N \backslash s} \frac{m_{j}}{M}\left[u_{i}^{\prime}\left(m_{i} \frac{M_{s}}{M}\right)-u_{i}^{\prime}\left(w_{i}-m_{i} \frac{M-M_{s}-m_{i}+m_{j}}{M}\right)\right] .
$$

For all $s \in S$ and $j \in N \backslash s$, let $b_{i i}(s, \mathbf{m})=m_{i}\left(M_{s} / M\right)$ and $b_{i j}(s, \mathbf{m})=w_{i}-m_{i}(M-$ $\left.M_{s}-m_{i}+m_{j}\right) / M$. Then

$$
\frac{\partial E u_{i}}{\partial m_{i}}=\left(1-\frac{m_{i}}{M}\right) \sum_{k=1}^{n} p_{k} \sum_{s \in S_{i}^{(k-1)}} \sum_{j \in N \mid s} \frac{m_{j}}{M}\left[u_{i}^{\prime}\left(b_{i i}(s, \mathbf{m})\right)-u_{i}^{\prime}\left(b_{i j}(s, \mathbf{m})\right)\right] .
$$

In particular, when $\mathbf{m}=\mathbf{w}=\left(w_{1}, \ldots, w_{n}\right)$, and letting $W=\sum_{i \in N} w_{i}$ and, for all $s \in S, W_{s}=W-\sum_{i \in s} w_{i}$ (the remaining wealth after firms in $s$ have burnt), we get

$$
\begin{aligned}
\left.\frac{\partial E u_{i}}{\partial m_{i}}\right|_{\mathbf{m}=\mathbf{w}}= & \left(1-\frac{w_{i}}{W}\right) \sum_{k=1}^{n} p_{k} \sum_{s \in S_{i}^{(k-1)}} \sum_{j \in N \backslash s} \frac{w_{j}}{W} \\
& \times\left[u_{i}^{\prime}\left(w_{i} \frac{W_{s}}{W}\right)-u_{i}^{\prime}\left(w_{i} \frac{\left.W_{s}-w_{i}+w_{j}\right)}{W}\right)\right] .
\end{aligned}
$$

Suppose that, for some $i, j \in N, w_{i} \neq w_{j}$. Then clearly $w_{n}>w_{1}$, implying that $\left.\left(\partial E u_{1} / \partial m_{1}\right)\right|_{\mathbf{m}=\mathbf{w}}<0$ and $\left.\left(\partial E u_{n} / \partial m_{n}\right)\right|_{\mathbf{m}=\mathbf{w}}>0$. In words, the poorest (respectively the richest) household has strict incentives to underreport (overreport), and $\mathbf{w}=\left(w_{1}, \ldots, w_{n}\right)$ is not a Nash equilibrium of the La Crema game. If, on the contrary, $w_{1}=w_{n}=\mathbf{w}$, then, for all $i \in N, w_{i}=\mathbf{w}$ and $\left.\left(\partial E u_{i} / \partial m_{i}\right)\right|_{\mathbf{m}=\mathbf{w}}=0$, implying that $\mathbf{w}=\left(w_{1}, \ldots, w_{n}\right)$ is a Nash equilibrium of the La Crema game. Q.E.D.

\section{Proof of Remark 1}

We proceed in five steps.

1. Let us show first that $\left(m_{1}, m_{2}\right)$ with $m_{i} \neq 0$ and $m_{i} \neq 2 C$ for all $i \in\{1,2\}$ cannot be an equilibrium. If $m^{\prime}=\left(m_{1}, m_{2}\right)$ were an equilibrium, we would have

$$
\begin{aligned}
\left\{\begin{array}{l}
\left|\frac{\partial E u_{1}}{\partial m_{1}}\right|_{\mathbf{m}=t^{\prime}}=0 \\
\left|\frac{\partial E u_{2}}{\partial m_{2}}\right|_{\mathbf{m}=t^{\prime}}=0
\end{array}\right\} \Leftrightarrow\left\{\begin{array}{l}
\frac{m_{1} m_{2}}{m_{1}+m_{2}}=w_{1}-\frac{m_{1} m_{2}}{m_{1}+m_{2}} \\
\frac{m_{1} m_{2}}{m_{1}+m_{2}}=w_{2}-\frac{m_{1} m_{2}}{m_{1}+m_{2}}
\end{array}\right\} \\
\\
\Leftrightarrow\left\{\begin{array}{l}
w_{1}=2 \frac{m_{1} m_{2}}{m_{1}+m_{2}} \\
w_{2}=2 \frac{m_{1} m_{2}}{m_{1}+m_{2}}
\end{array}\right\},
\end{aligned}
$$

which is impossible. 
2. The profile $\left(m_{1}^{\prime}, 0\right)$, with $m_{1}^{\prime} \neq 0$, cannot be an equilibrium since

$$
\left|\frac{\partial E u_{2}}{\partial m_{2}}\right|_{\mathbf{m}=\left(m_{1}^{\prime}, 0\right)}=p_{1}\left[u_{2}^{\prime}(0)-u_{2}^{\prime}\left(w_{2}\right)\right]>0 .
$$

Similarly, $\left(0, m_{2}^{\prime}\right)$, with $m_{2}^{\prime} \neq 0$, cannot be an equilibrium.

3 . The profile $\left(2 C, m_{2}\right)$ is not a Nash equilibrium. To see this, notice that the best response to $2 C$ is $m_{2}^{\prime}=2 w_{2} C /\left(4 C-w_{2}\right)$, since $\left.\left(\partial E u_{2} / \partial m_{2}\right)\right|_{\mathbf{m}=\left(2 C, m_{2}\right)}=0$, and $m_{2}=0, m_{2}=2 C$ produce lower payoffs than $m_{2}^{\prime}$ against $2 C$. However, the best response to $2 w_{2} C /\left(4 C-w_{2}\right)$ is not $2 C$, but rather

$$
m_{1}=\left(w_{1} \frac{2 w_{2} C}{4 C-w_{2}}\right) /\left(\frac{4 w_{2} C}{4 C-w_{2}}-w_{1}\right)
$$

(which by assumption is smaller than $2 C$, since one can directly verify that this expression is less than $2 C$ whenever $w_{1}<w_{2}$ ).

4. The profile $\left(2 w_{1} C /\left(4 C-w_{1}\right), 2 C\right)$ is a Nash equilibrium. First, the unique best response to $2 C$ is $m_{1}^{\prime}=2 w_{1} C /\left(4 C-w_{1}\right)$. This also implies that $\left(m_{1}, 2 C\right)$ with $m_{1} \neq 2 w_{1} C /\left(4 C-w_{1}\right)$ is not an equilibrium. Then notice that the only point $m_{2}^{\prime}$ at which $\left.\left(\partial E u_{2} / \partial m_{2}\right)\right|_{\mathbf{m}=\left(m_{1}, m_{2}\right)}=0$ is

$$
m_{2}^{\prime}=\left(w_{2} \frac{2 w_{1} C}{4 C-w_{1}}\right) /\left(\frac{4 w_{1} C}{4 C-w_{1}}-w_{2}\right),
$$

and by assumption $m_{2}^{\prime}<0$ (note that the denominator is less than zero if and only if $\left.w_{1}\left[1+\left(w_{2} / 4 C\right)\right]<w_{2}\right)$. Also,

$$
\left|\frac{\partial E u_{2}}{\partial m_{2}}\right|_{\mathbf{m}=\left(m_{1}^{\prime}, 0\right)}=p_{1}\left[u_{2}^{\prime}(0)-u_{2}^{\prime}\left(w_{2}\right)\right]>0,
$$

which, added to the fact that $m_{2}^{\prime}<0$ and continuity, implies that $\left.\left(\partial E u_{2} / \partial m_{2}\right)\right|_{\mathbf{m}=\left(m_{1}^{\prime}, C\right)}>0$.

5 . The only remaining case is $\mathbf{m}=(0,0)$. This is trivially an equilibrium. The payoff to any player $i$ in this case is that of autarchy, independently of the choice of $m_{i}$. Q.E.D.

Proof of Proposition 2

Let $\mathbf{c} \in \mathbb{R}^{2^{n}}$ be a consumption vector and $\operatorname{MRS}_{i}^{r s}(\mathbf{c})=\left(p_{r} \partial u_{i} / \partial c_{r}\right) /\left(p_{s} \partial u_{i} / \partial c_{s}\right)$ denote the marginal rate of substitution of player $i \in N$ between two states $r, s \in$ $S$ with respective probabilities $p_{r}$ and $p_{s}$. Pareto-efficient allocations are characterized by equal marginal rates of substitution across all agents in $N$ for all states in $S$. In particular, given a message vector $\mathbf{m} \in[0,2 C]^{n}$ and $r, s \in S^{(1)} \backslash\left\{S_{i}^{(0)} \cup\right.$ $\left.S_{j}^{(0)}\right\}, \operatorname{MRS}_{i}^{r, s}(\mathbf{c}(\mathbf{m}))=\operatorname{MRS}_{j}^{r, s}(\mathbf{c}(\mathbf{m}))$ is equivalent to

$$
\frac{u_{i}^{\prime}\left(w_{i}-m_{i} \frac{M-M_{r}}{M}\right)}{u_{i}^{\prime}\left(w_{i}-m_{i} \frac{M-M_{s}}{M}\right)}=\frac{u_{j}^{\prime}\left(w_{j}-m_{j} \frac{M-M_{r}}{M}\right)}{u_{j}^{\prime}\left(w_{j}-m_{j} \frac{M-M_{s}}{M}\right)}
$$


With identical CRRA utility functions, we get

$$
\frac{w_{i}-m_{i} \frac{M-M_{r}}{M}}{w_{i}-m_{i} \frac{M-M_{s}}{M}}=\frac{w_{j}-m_{j} \frac{M-M_{r}}{M}}{w_{j}-m_{j} \frac{M-M_{s}}{M}} \Leftrightarrow\left(M_{s}-M_{r}\right)\left(m_{i} w_{j}-m_{j} w_{i}\right)=0 .
$$

Therefore, either there exists some $\lambda \in \mathbb{R}$ such that $m_{k}=\lambda w_{k}$, for all $k \in N$, or $m_{k}=m_{l}=m$, for all $k, l \in N$. Now, let $s=S_{i}^{(0)}$ and $r \in S^{(1)} \backslash\left\{S_{i}^{(0)} \cup S_{j}^{(0)}\right\}$. Then $\operatorname{MRS}_{i}^{r, s}(\mathbf{c}(\mathbf{m}))=\operatorname{MRS}_{j}^{r, s}(\mathbf{c}(\mathbf{m}))$ is equivalent to

$$
\frac{w_{i}-m_{i} \frac{M-M_{r}}{M}}{m_{i}-m_{i} \frac{m_{i}}{M}}=\frac{w_{j}-m_{j} \frac{M-M_{r}}{M}}{w_{j}-m_{j} \frac{m_{i}}{M}} .
$$

If $m_{k}=m$ for all $k \in N$, this expression is equivalent to $\left[w_{j}-(m / n)\right] /[m-$ $(m / n)]=1$ for all $i, j \in N$, which is incompatible with $w_{i} \neq w_{j}$ for some $i, j \in$ $N$. We are thus left with $m_{k}=\lambda w_{k}$, for all $k \in N$ for some $\lambda \in \mathbb{R}$. Let $s \in S_{i}^{(0)}$ and $r \in S^{(0)}$. Then $\operatorname{MRS}_{i}^{r, s}(\mathbf{c}(\mathbf{m}))=\operatorname{MRS}_{j}^{r, s}(\mathbf{c}(\mathbf{m}))$ is equivalent to

$$
\frac{m_{i}-m_{i}\left(m_{i} / M\right)}{w_{i}}=\frac{w_{j}-m_{j}\left(m_{i} / M\right)}{w_{j}} \Leftrightarrow \lambda=1 .
$$

Moreover, it is easy to check that all other marginal rates of substitution are equalized across agents when $m_{i}=w_{i}$ for all $i \in N$. Q.E.D.

\section{Proof of Remark 2}

Let the Walrasian price for a unit of consumption in state $s$ be $q_{s}$. The efficient allocation of La Crema leads to consumption of $w_{i}\left(W_{s} / W\right)$ for agent $i$ in state $s$. Assume, for a contradiction, that the efficient allocation is a Walrasian equilibrium. The budget constraint is given by

$$
\sum_{s \in S} q_{s} \frac{w_{i} W_{s}}{W}=\sum_{s \notin S_{i}} q_{s} w_{i},
$$

and dividing on both sides of the equation by $w_{i}$, we obtain

$$
\sum_{s \in S} q_{s} \frac{W_{s}}{W}=\sum_{s \notin S_{i}} q_{s}
$$

Optimality requires that the marginal rate of substitution between any two states $r, s$ is equal to the ratio of consumption prices between these states. Let us normalize the price of consumption in the state in which no farm burns $(r=\{0\})$ to one. This implies that

$$
\frac{p_{s} u_{i}^{\prime}\left(w_{i}\left(w_{S} / w\right)\right)}{p_{0} u_{i}^{\prime}\left(w_{i}\right)}=\frac{p_{s}\left[w_{i}\left(W_{s} / W\right)\right]^{\alpha-1}}{p_{0} w_{i}^{\alpha-1}}=\frac{p_{s}}{p_{\{0\}}}\left(\frac{W_{s}}{W}\right)^{\alpha-1}=q_{s} .
$$

When the price is substituted in (A3), it follows that, for each $i$,

$$
\sum_{s \in S} \frac{p_{s}}{p_{0}}\left(\frac{W_{s}}{W}\right)^{\alpha}=\sum_{s \notin S_{i}} \frac{p_{s}}{p_{0}}\left(\frac{W_{s}}{W}\right)^{\alpha-1} .
$$


Eliminating the $p_{0}$, we have

$$
\sum_{s \in S} p_{s}\left(\frac{W_{s}}{W}\right)^{\alpha}=\sum_{s \notin S_{i}} p_{s}\left(\frac{W_{s}}{W}\right)^{\alpha-1}
$$

Let $S^{-i}$ denote the states that would exist if $i$ were not in the economy. So $S$ has twice as many states as $S^{-i}$. For $s^{\prime} \in S^{-i}$, let $W_{s^{\prime}}$ be the wealth in state $s^{\prime}$ if $i$ were not in the economy. Keep $W$ as the total wealth including $i$ and $p$ as the probability that a farm burns. We rewrite the expression above as

$$
\sum_{s^{\prime} \in S^{-i}} p_{s^{\prime}}\left[(1-p)\left(\frac{W_{s^{\prime}}+w_{i}}{W}\right)^{\alpha}+p\left(\frac{W_{s^{\prime}}}{W}\right)^{\alpha}\right]=\sum_{s^{\prime} \in S^{-i}} p_{s^{\prime}}(1-p)\left(\frac{W_{s^{\prime}}+w_{i}}{W}\right)^{\alpha-1} .
$$

Rearranging terms, we get that

$$
\sum_{s^{\prime} \in S^{-i}} p_{s^{\prime}}\left\{(1-p)\left(\frac{W_{s^{\prime}}+w_{i}}{W}\right)^{\alpha}\left[1-\left(\frac{W_{s^{\prime}}+w_{i}}{W}\right)^{-1}\right]+p\left(\frac{W_{s^{\prime}}}{W}\right)^{\alpha}\right\}=0
$$

must hold for each $i$. Now, let $S^{-j, k}$ denote the set of states in which neither $j$ nor $k$ is in the economy. Rewriting (A4), when $i=j$ we get that

$$
\begin{gathered}
\sum_{s^{\prime \prime} \in S^{-j, k}} p_{s^{\prime \prime}}\left\{(1-p)^{2}\left(\frac{W_{s^{\prime \prime}}+w_{j}+w_{k}}{W}\right)^{\alpha}\left[1-\left(\frac{W_{s^{\prime \prime}}+w_{j}+w_{k}}{W}\right)^{-1}\right]\right. \\
+(1-p) p\left(\frac{W_{s^{\prime \prime}}+w_{j}}{W}\right)^{\alpha}\left[1-\left(\frac{W_{s^{\prime \prime}}+w_{j}}{W}\right)^{-1}\right] \\
\left.+p(1-p)\left(\frac{W_{s^{\prime \prime}}+w_{k}}{W}\right)^{\alpha}+p^{2}\left(\frac{W_{s^{\prime \prime}}}{W}\right)^{\alpha}\right\}=0 .
\end{gathered}
$$

Similarly, from $k$ 's perspective, we get

$$
\begin{gathered}
\sum_{s^{\prime \prime} \in S^{-j, k}} p_{s^{\prime \prime}} \mid(1-p)^{2}\left(\frac{W_{s^{\prime \prime}}+w_{j}+w_{k}}{W}\right)^{\alpha}\left[1-\left(\frac{W_{s^{\prime \prime}}+w_{j}+w_{k}}{W}\right)^{-1}\right] \\
+(1-p) p\left(\frac{W_{s^{\prime \prime}}+w_{k}}{W}\right)^{\alpha}\left[1-\left(\frac{W_{s^{\prime \prime}}+w_{k}}{W}\right)^{-1}\right] \\
\left.+p(1-p)\left(\frac{W_{s^{\prime \prime}}+w_{j}}{W}\right)^{\alpha}+p^{2}\left(\frac{W_{s^{\prime \prime}}}{W}\right)^{\alpha}\right\}=0 .
\end{gathered}
$$

Subtracting (A6) from (A5), we get

$$
\sum_{s^{\prime \prime} \in S^{-j, k}} p_{s^{\prime \prime}}(1-p) p\left[\left(\frac{W_{s^{\prime \prime}}+w_{k}}{W}\right)^{\alpha-1}-\left(\frac{W_{s^{\prime \prime}}+w_{j}}{W}\right)^{\alpha-1}\right]=0 .
$$

But this cannot hold if $w_{k}<w_{j}$ or if $w_{k}>w_{j}$, which is a contradiction. Q.E.D. 
Proof of Proposition 3

Let us first consider $n \geq 3$. Given a message vector $\mathbf{m} \in[0,2 C]^{n}$ and $r \in S^{(1)} \backslash$ $\left\{S_{i}^{(0)} \cup S_{j}^{(0)}\right\}, s \in S^{(0)}, \operatorname{MRS}_{i}^{r s}(\mathbf{c}(\mathbf{m}))=\operatorname{MRS}_{j}^{r, s}(\mathbf{c}(\mathbf{m}))$ is equivalent with identical CARA utility functions to

$$
w_{i}-m_{i} \frac{M-M_{r}}{M}-w_{i}=w_{j}-m_{j} \frac{M-M_{r}}{M}-w_{j} \Leftrightarrow m_{i}=m_{j}
$$

Now, let $r \in S_{i}^{(0)}, s \in S^{(0)}$. Then $\operatorname{MRS}_{i}^{r, s}(\mathbf{c}(\mathbf{m}))=\operatorname{MRS}_{j}^{r, s}(\mathbf{c}(\mathbf{m}))$ is equivalent to

$$
m_{i}-m_{i} \frac{m_{i}}{M}-w_{i}=w_{j}-m_{j} \frac{m_{i}}{M}-w_{j} .
$$

Since $m_{i}=m_{j}$, this is equivalent to

$$
m_{i}-m_{i} \frac{m_{i}}{M}-w_{i}=-m_{i} \frac{m_{i}}{M} \Leftrightarrow m_{i}=w_{i}
$$

Similarly we can also show that $m_{j}=w_{j}$, which is a contradiction with $m_{i}=$ $m_{j}$ and $w_{i} \neq w_{j}$. Now let $n=2$. Then, for $r \in S_{1}^{(0)}$ and $s \in S^{(0)}, \operatorname{MRS}_{1}^{1,0}(\mathbf{c}(\mathbf{m}))=$ $\operatorname{MRS}_{2}^{1,0}(\mathbf{c}(\mathbf{m}))$ is equivalent to

$$
m_{1}-m_{1} \frac{m_{1}}{m_{1}+m_{2}}-w_{1}=-m_{1} \frac{m_{2}}{m_{1}+m_{2}} \Leftrightarrow w_{1}=m_{1} \frac{m_{2}}{m_{1}+m_{2}}
$$

Similarly we can show that $w_{2}=m_{2}\left[m_{1} /\left(m_{1}+m_{2}\right)\right]$, which is a contradiction with $w_{1} \neq w_{2}$. Q.E.D.

\section{Proof of Remark 3}

Let a message vector $\mathbf{m} \in[\mathbf{0}, 2 \mathbf{C}]^{n}$ and $r, \quad s \in S^{(1)} \mid\left\{S_{i}^{(0)} \cup S_{j}^{(0)}\right\}$. Then $\operatorname{MRS}_{1}^{r, s}(\mathbf{c}(\mathbf{m}))=\operatorname{MRS}_{i}^{r, s}(\mathbf{c}(\mathbf{m}))$ is equivalent with CRRA utility functions to

$$
1=\frac{w_{i}-m_{i} \frac{M-M_{r}}{M}}{w_{i}-m_{i} \frac{M-M_{s}}{M}} \Leftrightarrow M_{r}=M_{s} .
$$

Now, let $s \in S_{i}^{(0)}$ and $r \in S^{(1)} \backslash\left\{S_{i}^{(0)} \cup S_{j}^{(0)}\right\}$. Then $\operatorname{MRS}_{1}^{s, r}(\mathbf{c}(\mathbf{m}))=\operatorname{MRS}_{i}^{s, r}(\mathbf{c}(\mathbf{m}))$ is

$$
1=\frac{w_{i}-m_{i} \frac{m_{i}}{M}}{w_{i}-m_{i} \frac{m_{s}}{M}} \Leftrightarrow w_{i}=m_{i} .
$$

The previous two equalities imply that $w_{i}=w_{j}$, which is a contradiction. Q.E.D. 
Proof of Proposition 4

Fix $h$. We bound $\partial E u_{i}(\mathbf{w}) / \partial m_{i}$ by an expression that is decreasing in $n^{h}$.

From (A2) we know that

$$
\begin{aligned}
\left|\frac{\partial E u_{i}}{\partial m_{i}}\right|_{\mathbf{m}=\mathbf{w}}= & \left(1-\frac{w_{i}}{W}\right) \sum_{k=1}^{n} p_{k} \sum_{s \in S_{i}^{(k-1)}} \sum_{j \in N \backslash s} \frac{w_{j}}{W} \\
& \times\left[u_{i}^{\prime}\left(w_{i} \frac{W_{s}}{W}\right)-u_{i}^{\prime}\left(w_{i} \frac{W_{s}-w_{i}+w_{j}}{W}\right)\right] .
\end{aligned}
$$

This implies that

$$
\left|\frac{\partial E u_{i}}{\partial m_{i}}\right|_{\mathbf{m}=\mathbf{w}}<\max _{s \in S_{i}^{(i-1)}, j \notin s}\left|u_{i}^{\prime}\left(w_{i} \frac{W_{s}}{W}\right)-u_{i}^{\prime}\left(w_{i} \frac{W_{s}-w_{i}+w_{j}}{W}\right)\right| .
$$

Note that

$$
\left|w_{i} \frac{W_{s}}{W}-w_{i} \frac{W_{s}-w_{i}+w_{j}}{W}\right|<C \frac{C-c}{n^{h} c} .
$$

Then by (A7) and assumption 1 , for any $\mu>0$, we can find $H_{\mu}$ such that, for any $h>H_{\mu}$,

$$
\left|\frac{\partial E u_{i}}{\partial m_{i}}\right|_{\mathbf{m}=\mathbf{w}}<\mu
$$

for all $i \in N^{h}$. Finally, given any $\epsilon$, choose $\mu$ such that $\mu=\epsilon / 2 C$. Given the strict concavity of $u_{i}$, it follows that the maximal gain from a report of some $m_{i}$ instead of $w_{i}$ is $2 C\left|\partial E u_{i} / \partial m_{i}\right|<\epsilon$ for all $i \in N^{h}$, where $h>H_{\mu}$. This establishes the proposition. Q.E.D.

\section{Proof of Proposition 6}

Let $\sigma$ be a nondegenerate Nash equilibrium of the La Crema game. Consider $i$ and a strategy profile $\sigma_{-i}$ that does not place probability one on all players $j \neq i$ playing 0 . From (A1) we know that

$$
\frac{\partial E u_{i}(\mathbf{m})}{\partial m_{i}}=\left(1-\frac{m_{i}}{M}\right) \sum_{k=1}^{n} p_{k} \sum_{s \in S_{i}^{(k-1)}} \sum_{j \in N \mid s} \frac{m_{j}}{M}\left[u_{i}^{\prime}\left(b_{i i}(s, \mathbf{m})\right)-u_{i}^{\prime}\left(b_{i j}(s, \mathbf{m})\right)\right],
$$

where $b_{i i}$ and $b_{i j}$ are as defined in the proof of proposition 1. Consider any strategy profile $m_{i}, \sigma_{-i}$ :

$$
\begin{aligned}
\frac{\partial E u_{i}\left(m_{i}, \sigma_{-i}\right)}{\partial m_{i}}= & \int\left\{( 1 - \frac { m _ { i } } { M } ) \sum _ { k = 1 } ^ { n } p _ { k } \sum _ { s \in S _ { i } ^ { ( k - 1 ) } } \sum _ { j \in N \backslash s } \frac { m _ { j } } { M } \left[u_{i}^{\prime}\left(b_{i i}(s, \mathbf{m})\right)\right.\right. \\
& \left.\left.-u_{i}^{\prime}\left(b_{i j}(s, \mathbf{m})\right)\right]\right\} d \sigma_{-i}\left(m_{-i}\right)
\end{aligned}
$$

Note that we can reverse the order of integration with respect to $m_{-i}$ and derivation with respect to $m_{i}$ (i.e., differentiate inside the integral in getting expression [A8]) because the function $\partial E u_{i}\left(m_{i}, \sigma_{-i}\right) / \partial m_{i}$ of $m_{i}$ is bounded on player 
$i$ 's strategy set $[0,2 C]$ for all $\sigma_{-i}$. Note that (A8) implies that any strategy with $m_{i}<w_{i} / 2$ is weakly dominated. This follows from noting that $b_{i i}(s, \mathbf{m})<m_{i}$ and $b_{i j}(s, \mathbf{m}) \geq w_{i}-m_{i}$ for any $s$ and $m_{-i}$, and so given the strict concavity of $u_{i}$, the expression is strictly positive regardless of $s$ and $m_{-i}$, provided that $m_{i}<w_{i} / 2$.

Let $\left(s^{*}, \mathbf{m}^{*}\right)$ minimize $u_{i}^{\prime}\left(b_{i i}\left(s^{*}, \mathbf{m}^{*}\right)\right)-u_{i}^{\prime}\left(b_{i j}\left(s^{*}, \mathbf{m}^{*}\right)\right)$ over the support of $m_{i}, \sigma_{-i}$. Equation (A8) and the concavity of $u_{i}$ also imply that

$$
\begin{aligned}
\frac{\partial E u_{i}\left(m_{i}, \sigma_{-i}\right)}{\partial m_{i}} \geq & \int\left\{( 1 - \frac { m _ { i } } { M } ) \sum _ { k = 1 } ^ { n } p _ { k } \sum _ { s \in S _ { i } ^ { ( k - 1 ) } } \sum _ { j \in N \backslash s } \frac { m _ { j } } { M } \left[u_{i}^{\prime}\left(b_{i i}\left(s^{*}, \mathbf{m}^{*}\right)\right)\right.\right. \\
& \left.\left.-u_{i}^{\prime}\left(b_{i j}\left(s^{*}, \mathbf{m}^{*}\right)\right)\right]\right\} d \sigma_{-i}\left(m_{-i}\right) .
\end{aligned}
$$

Thus

$$
\begin{aligned}
\frac{\partial E u_{i}\left(m_{i}, \sigma_{-i}\right)}{\partial m_{i}} \geq & {\left[u_{i}^{\prime}\left(b_{i i}\left(s^{*}, \mathbf{m}^{*}\right)\right)-u_{i}^{\prime}\left(b_{i j}\left(s^{*}, \mathbf{m}^{*}\right)\right)\right] } \\
& \times \int\left(1-\frac{m_{i}}{M}\right) \sum_{k=1}^{n} p_{k} \sum_{s \in S_{i}^{(k-1)}} \sum_{j \in N \mid s} \frac{m_{j}}{M} d \sigma_{-i}\left(m_{-i}\right) .
\end{aligned}
$$

Given that $\sigma_{-i}$ does not place probability one on all players $j \neq i$ playing 0 , the integral on the right-hand side of (A9) is strictly positive. Then it follows from (A9) that $0 \geq \partial E u_{i}\left(m_{i}, \sigma_{-i}\right) / \partial m_{i}$ implies that

$$
0 \geq u_{i}^{\prime}\left(b_{i i}\left(s^{*}, \mathbf{m}^{*}\right)\right)-u_{i}^{\prime}\left(b_{i j}\left(s^{*}, \mathbf{m}^{*}\right)\right) .
$$

Thus, given assumption $1,0 \geq \partial E u_{i}\left(m_{i}, \sigma_{-i}\right) / \partial m_{i}$ implies that $b_{i i}\left(s^{*}, \mathbf{m}^{*}\right) \geq b_{i j}\left(s^{*}\right.$, $\mathbf{m}^{*}$ ), which can be rewritten as

$$
m_{i} \geq \frac{w_{i}}{1+\left[\left(m_{i}-m_{j}^{*}\right) / M^{*}\right]} .
$$

Note that $1 \geq\left(m_{i}-m_{j}^{*}\right) / M^{*} \geq-1$. Then it follows from (A10) that if $\sigma_{-i}$ does not place probability one on all players $j \neq i$ playing 0 , then a best reply by $i$ must have support only on $m_{i} \geq w_{i} / 2$. This then implies that if $\sigma$ is a mixed-strategy equilibrium that does not place probability one on $(0, \ldots, 0)$, it must be that the support of each $\sigma_{j}$ is a subset of $\left[w_{j} / 2,2 C\right]$. This implies that $4 C / W \geq$ $\left(m_{i}-m_{j}^{*}\right) / M^{*}$, and so from (A10) it follows that if $\sigma$ is a mixed-strategy equilibrium that does not place probability one on $(0, \ldots, 0)$, it must be that, for each $i$ and any $m_{i}$ that is a best response to $\sigma_{-i}$,

$$
m_{i} \geq \frac{w_{i}}{1+(4 C / W)}
$$

Let $\left(s^{* *}, \mathbf{m}^{* *}\right)$ maximize $u_{i}^{\prime}\left(b_{i i}\left(s^{* *}, \mathbf{m}^{* *}\right)\right)-u_{i}^{\prime}\left(b_{i j}\left(s^{* *}, \mathbf{m}^{* *}\right)\right)$ over the support of $m_{i}$, $\sigma_{-i}$. If $\sigma_{-i}$ has the support of each $\sigma_{j}$ as a subset of $\left[w_{j} / 2,2 C\right]$, then (A8) and the concavity of $u_{i}$ imply that

$$
\begin{gathered}
{\left[u_{i}^{\prime}\left(b_{i i}\left(s^{* *}, \mathbf{m}^{* *}\right)\right)-u_{i}^{\prime}\left(b_{i j}\left(s^{* *}, \mathbf{m}^{* *}\right)\right)\right] \int\left(1-\frac{m_{i}}{M}\right) \sum_{k=1}^{n} p_{k} \sum_{s \in S_{i}^{(k-1)}} \sum_{j \in N \backslash s} \frac{m_{j}}{M} d \sigma_{-i}\left(m_{-i}\right)} \\
\geq \frac{\partial E u_{i}\left(m_{i}, \sigma_{-i}\right)}{\partial m_{i}} .
\end{gathered}
$$


Thus $\partial E u_{i}\left(m_{i}, \sigma_{-i}\right) / \partial m_{i} \geq 0$ implies

$$
\frac{w_{i}}{1+\left[\left(m_{i}-m_{j}^{* *}\right) / M^{* *}\right]} \geq m_{i}
$$

Since $4 C / W \geq\left(m_{i}-m_{j}^{* *}\right) / M^{* *}$, it follows that

$$
\frac{w_{i}}{1-(4 C / W)} \geq m_{i}
$$

and (A11) and (A13) establish the proposition. Q.E.D.

Proof of Proposition 5

The fact that any pure-strategy nondegenerate equilibrium involves only play of $m_{i} \geq w / 2$ such that $4 C^{2} / W \geq\left|m_{i}-w_{i}\right|$ follows directly from the proof of proposition 6. Let us show that there exists such an equilibrium and that it is a strict equilibrium. We do this by showing that to any best response of $m_{-i}$ such that $m_{j} \in\left[w_{j} / 2,2 C\right]$, there is a unique best response (which then must be in $\left[w_{i} / 2,2 C\right]$ by proposition 6 ) that varies continuously in $m_{-i}$. The result then follows from Kakutani's theorem.

From the proof of proposition 6 it follows that $\partial E u_{i}(\mathbf{m}) / \partial m_{i}$ is continuous in $m_{i}$ and $m_{-i}$ and that $\partial E u_{i}(\mathbf{m}) / \partial m_{i}>0$ if $m_{i}<w_{i} / 2$, and $\partial E u_{i}(\mathbf{m}) / \partial m_{i}<0$ if $m_{i}>$ $w_{i} /[1-(4 C / W)]$. Thus there exists a point $m_{i} \in\left[w_{i} / 2, w_{i}[1-(4 C / W)]\right]$ at which $\partial E u_{i}(\mathbf{m}) / \partial m_{i}=0$. We show that, at any such point, $\partial^{2} E u_{i}(\mathbf{m}) / \partial m_{i}^{2}<0$. This implies that there are no local minima, which in turn implies that there is a unique such point. Direct calculation gives

$$
\begin{aligned}
\frac{\partial b_{i i}}{\partial m_{i}} & =\left(1-\frac{m_{i}}{M}\right)\left(\frac{M_{s}}{M}\right), \\
\frac{\partial b_{i j}}{\partial m_{i}} & =-\frac{M-m_{i}}{M}\left(\frac{M-M_{s}-m_{i}+m_{j}}{M}\right) \quad \forall j \neq i, \\
\frac{\partial}{\partial m_{i}}\left[\frac{m_{j}}{M}\left(1-\frac{m_{i}}{M}\right)\right] & =-\frac{2 m_{j}}{M^{2}}\left(1-\frac{m_{i}}{M}\right),
\end{aligned}
$$

leading to

$$
\begin{aligned}
& \frac{\partial^{2} E u_{i}(\mathbf{m})}{\partial m_{i}^{2}}= \\
& \frac{\left(1-\frac{m_{i}}{M}\right) \sum_{k=1}^{n} p_{k} \sum_{s \in S_{i}^{(k-1)}} \sum_{j \in N \backslash s} \frac{m_{j}}{M} u_{i}^{\prime \prime}\left(b_{i i}\right)\left(1-\frac{m_{i}}{M}\right)\left(\frac{M_{s}}{M}\right)}{<0} \\
& +\left(1-\frac{m_{i}}{M}\right) \sum_{k=1}^{n} p_{k} \sum_{s \in S_{i}^{(k-1)}} \sum_{j \in N \backslash s} \frac{m_{j}}{M} u_{i}^{\prime \prime}\left(b_{i j}\right)\left(\frac{M-m_{i}}{M}\right)\left(\frac{M-M_{s}-m_{i}+m_{j}}{M}\right) \\
& -\left(1-\frac{m_{i}}{M}\right) \sum_{k=1}^{n} p_{k} \sum_{s \in S_{i}^{(k-1)}} \sum_{j \in N \backslash s} \frac{2 m_{j}}{M^{2}}\left[u_{i}^{\prime}\left(b_{i i}\right)-u_{i}^{\prime}\left(b_{i j}\right)\right] .
\end{aligned}
$$


This second expression is $-(2 / M)\left[\partial E u_{i}(\mathbf{m}) / \partial m_{i}\right]$, and so the whole expression is negative whenever $\partial E u_{i}(\mathbf{m}) / \partial m_{i} \geq 0$. This concludes the proof. Q.E.D.

\section{Proof of Proposition 7}

We prove part $\mathrm{i}$, since then part ii follows in a straightforward way from proposition 5 (and assumption 2). Let $\bar{W}^{h}=E^{h}\left[W_{s}^{h}\right]$. The weak law of large numbers ${ }^{29}$ implies that

$$
\operatorname{Prob}^{h}\left[\left|\frac{W_{s}^{h}-\bar{W}^{h}}{W^{h}}\right| \geq \epsilon\right] \rightarrow 0
$$

for any $\epsilon>0$. It follows from (A14), the continuity, and bounds on $u_{i}$ that for any $\epsilon>0$ there exists $H$ such that

$$
\operatorname{Prob}^{h}\left[\left|u_{i}\left(w_{i} \frac{W_{s}^{h}}{W^{h}}\right)-u_{i}\left(w_{i} \frac{\bar{W}^{h}}{W^{h}}\right)\right| \geq \epsilon\right]<\epsilon
$$

for all $i \in N^{h}$ and any $h>H$. Let $x^{h}$ Pareto-dominate $x^{w, h}$. Suppose to the contrary of the proposition that there exists $\delta>0$ such that

$$
\frac{\sum_{i \in N^{h}} E u_{i}\left(x^{h}\right)-E u_{i}\left(x^{w, h}\right)}{\sum_{i \in N^{h}} E u_{i}\left(x^{w, h}\right)}>\delta
$$

for infinitely many $h$. Let $\bar{x}^{h}=\left(E\left[x_{1}^{h}\right], \ldots, E\left[x_{n^{h}}^{h}\right]\right)$ be the expected value of $x^{h}$. Then by the concavity of $u_{i}$,

$$
\frac{\sum_{i \in N^{h}} u_{i}\left(\bar{x}^{h}\right)-E u_{i}\left(x^{w, h}\right)}{\sum_{i \in N^{h}} E u_{i}\left(x^{w, h}\right)}>\delta
$$

for infinitely many $h$. Given assumption 2, it follows from (A16) and the fact that $x^{h}$ Pareto-dominates $x^{w, h}$ that for each such $h$ we can find some $\gamma>0$ and vector $\hat{\mathbf{x}}^{h}$ such that $\sum_{i \in N^{h}} \hat{x}_{i}^{h}=\sum_{i \in N^{h}} \bar{x}_{i}^{h}$ and

$$
u_{i}\left(\hat{x}_{i}^{h}\right)-E u_{i}\left(x_{i}^{w, h}\right)>\gamma
$$

for all $i \in N^{h}$. Then from (A15) it follows that

$$
u_{i}\left(\hat{x}_{i}^{h}\right)-u_{i}\left(w_{i} \frac{\bar{W}^{h}}{W^{h}}\right)>\gamma
$$

for all $i \in N^{h}$, for infinitely many $h$. However, as both $\hat{\mathbf{x}}^{h}$ and $w_{i}\left(\bar{W}^{h} / W^{h}\right)$ sum to $\bar{W}^{h}$, this is a contradiction. Q.E.D.

\footnotetext{
${ }^{29}$ We apply a version covering sequences of heterogeneous but independent random variables (see, e.g., Billingsley 1979, theorem 6.2). Note here that $\sigma^{h} / W^{h} \rightarrow 0$, where $\sigma^{h}$ is the standard deviation of $W_{s}^{h}$. This follows since $C \sqrt{n^{h} p(1-p)} \geq \sigma^{h}$ and $W^{h} \geq n c$.
} 


\section{Appendix B}

TABLE B1

la CRema: List of Damages, 1884-1950

\begin{tabular}{llcl}
\hline \hline Year & Farm Name & Value Damage & Date Payment \\
\hline 1884 & Casalé & 470 & December 24, 1886 \\
1885 & Jarca & 555 & January 4, 1887 \\
1885 & Planché & 2,75 & January 4, 1887 \\
1903 & Peret & 780 & October 3, 1906 \\
1903 & Mocho & 800 & October 3,1906 \\
1906 & Pascol & 50 & October 3, 1906 \\
1921 & Grabiel & 1,750 & December 9,1921 \\
1922 & Borronet & 40 & June 29, 1922 \\
1923 & Rauquet & 14,5 & April 2, 1923 \\
1922 & Borró & 8,5 & October 6,1923 \\
1926 & Jep & 2,000 & January 24, 1926 \\
1926 & Fluis & 10,5 & January 24, 1926 \\
1926 & Esclopet & 10,75 & January 24, 1926 \\
1926 & Jep & 1,300 & March 29, 1930 \\
1936 & Toni Forn & 1,800 & August 16, 1937 \\
1936 & Toni Forn & 750 & June 2, 1938 \\
1937 & Casalé & 80 & June 2, 1938 \\
1939 & Anraulat & 250 & June 12, 1939 \\
1942 & Vecaina & 50 & January 18, 1948 \\
1948 & Peretol & 3,165 & June 2, 1949 \\
1950 & Armany & 72 & February 2, 1950 \\
\hline
\end{tabular}

Source. - La Crema book, Benito Marquet Armengol, Cal Ton de Borró, Canillo.

TABLE B2

la Crema: Reported Valuations, 1929

\begin{tabular}{|c|c|c|c|c|c|c|c|c|c|}
\hline \multirow{2}{*}{$\begin{array}{l}\text { FARM NAME } \\
\text { Andrieta }\end{array}$} & \multirow{2}{*}{$\begin{array}{c}\text { VALUATION } \\
1,380\end{array}$} & \multirow{2}{*}{$\begin{array}{c}\text { Percent } \\
1.070\end{array}$} & \multirow{2}{*}{$\begin{array}{c}\text { House } \\
400\end{array}$} & \multirow{2}{*}{$\frac{\text { BARN }}{400}$} & \multicolumn{5}{|c|}{$\begin{array}{l}\text { Other Properties Insured } \\
\text { (Truncated at } 8 \text { ) }\end{array}$} \\
\hline & & & & & 400 & 50 & 80 & 50 & \\
\hline Anrauladet & 1,450 & 1.125 & 250 & 250 & 200 & 150 & 200 & 400 & \\
\hline Armany & 1,760 & 1.365 & 600 & 500 & 60 & 500 & 100 & & \\
\hline Asó & 450 & .349 & 200 & 200 & 50 & & & & \\
\hline Aleix & 820 & .636 & 250 & 100 & 50 & 160 & 160 & 50 & 50 \\
\hline Agustí Farré & 900 & .698 & 500 & 400 & & & & & \\
\hline Albellana & 900 & .698 & 300 & 100 & 150 & 200 & 150 & & \\
\hline Borronet & 1,750 & 1.357 & 600 & 500 & 450 & 200 & & & \\
\hline Borró & 1,020 & .791 & 550 & 450 & 20 & & & & \\
\hline Barnat & 350 & .271 & 200 & 150 & & & & & \\
\hline Bondancia & 941 & .730 & 130 & 300 & 90 & 15 & 200 & 190 & 16 \\
\hline Batista & 875 & .679 & 300 & 200 & 150 & 225 & & & \\
\hline Branqueta & 1,060 & .822 & 250 & 150 & 150 & 200 & 60 & 250 & \\
\hline Bacaró & 550 & .427 & 250 & 200 & 100 & & & & \\
\hline Bartoló & 1,850 & 1.435 & 500 & 400 & 300 & 350 & 250 & 50 & \\
\hline Barbet & 350 & .271 & 200 & 150 & & & & & \\
\hline Bonavida & 1,800 & 1.396 & 500 & 300 & 300 & 400 & 100 & 100 & 100 \\
\hline Borjes & 1,400 & 1.086 & 200 & 400 & 200 & 200 & 200 & 200 & \\
\hline Bartreta & 940 & .729 & 300 & 100 & 310 & 10 & 40 & 180 & \\
\hline Bitó & 660 & .512 & 160 & 250 & 250 & & & & \\
\hline Bregadós & 400 & .310 & 200 & 200 & & & & & \\
\hline Casadet & 1,050 & .814 & 300 & 300 & 350 & 100 & & & \\
\hline Call & 1,750 & 1.357 & 300 & 250 & 50 & 50 & 250 & 100 & 300 \\
\hline
\end{tabular}


TABLE B2

(Continued)

\begin{tabular}{|c|c|c|c|c|c|c|c|c|c|c|c|c|}
\hline \multirow{2}{*}{$\frac{\text { FARM NAME }}{\text { Casalé }}$} & \multirow{2}{*}{$\begin{array}{c}\text { VALUATION } \\
1,450\end{array}$} & \multirow{2}{*}{$\frac{\text { Percent }}{1.125}$} & \multirow{2}{*}{$\frac{\text { House }}{300}$} & \multirow{2}{*}{$\frac{\text { BARN }}{350}$} & \multicolumn{8}{|c|}{$\begin{array}{c}\text { Other Properties Insured } \\
\text { (Truncated at } 8 \text { ) }\end{array}$} \\
\hline & & & & & 500 & 50 & 250 & & & & & \\
\hline Candela & 300 & .233 & 150 & 150 & & & & & & & & \\
\hline \multicolumn{13}{|l|}{ Cabalé } \\
\hline Llecsia & 600 & .465 & 350 & 250 & & & & & & & & \\
\hline Hble. Comú & 658 & .510 & 160 & 128 & 160 & 110 & 100 & & & & & \\
\hline Concha & 1,750 & 1.357 & 500 & 500 & 500 & 100 & 150 & & & & & \\
\hline Calbó & 2,500 & 1.939 & 700 & 400 & 400 & 400 & 400 & 200 & & & & \\
\hline Comet & 600 & .465 & 200 & 200 & 200 & & & & & & & \\
\hline Canaro & 1,000 & .776 & 400 & 350 & 250 & & & & & & & \\
\hline Esclopet & 1,000 & .776 & 250 & 500 & 250 & & & & & & & \\
\hline Franca & 200 & .155 & 100 & 100 & & & & & & & & \\
\hline Francés & 1,070 & .830 & 300 & 450 & 200 & 80 & 40 & & & & & \\
\hline Farré nou & 280 & .217 & 200 & 80 & & & & & & & & \\
\hline Fluis & 400 & .310 & 150 & 150 & 100 & & & & & & & \\
\hline Fontana & 430 & .334 & 130 & 200 & 100 & & & & & & & \\
\hline Gastó & 1,140 & .884 & 300 & 300 & 20 & 60 & 60 & 200 & 200 & & & \\
\hline Gabachó & 1,300 & 1.008 & 400 & 400 & 300 & 200 & & & & & & \\
\hline Gabacha & 900 & .698 & 400 & 200 & 200 & 100 & & & & & & \\
\hline Grabiel & 1,400 & 1.086 & 500 & 450 & 350 & 100 & & & & & & \\
\hline Janramon & 1,350 & 1.047 & 400 & 400 & 250 & 150 & 150 & & & & & \\
\hline Jandelsastre & 920 & .714 & 270 & 250 & 300 & 50 & 50 & & & & & \\
\hline Jaumina & 1,350 & 1.047 & 500 & 400 & 400 & 50 & & & & & & \\
\hline Janet & 300 & .233 & 200 & 100 & & & & & & & & \\
\hline Jarca & 1,300 & 1.008 & 600 & 200 & 250 & 250 & & & & & & \\
\hline Janetó & 700 & .543 & 250 & 250 & 200 & & & & & & & \\
\hline Jordi & 1,100 & .853 & 400 & 350 & 200 & 150 & & & & & & \\
\hline Jumpere & 1,970 & 1.528 & 400 & 400 & 200 & 150 & 350 & 60 & 300 & 50 & 60 & \\
\hline Jep & 1,900 & 1.474 & 200 & 600 & 300 & 100 & 600 & 100 & & & & \\
\hline Jesuita & 200 & .155 & 200 & & & & & & & & & \\
\hline Jaunsaus & 1,250 & .970 & 200 & 150 & 300 & 600 & & & & & & \\
\hline Jove Victorio & 1,235 & .958 & 300 & 250 & 225 & 225 & 175 & 60 & & & & \\
\hline Jaume Goral & 600 & .465 & 600 & & & & & & & & & \\
\hline \multicolumn{13}{|l|}{ Josep } \\
\hline Escribá & 400 & .310 & 400 & & & & & & & & & \\
\hline Hostet & 2,300 & 1.784 & 600 & 600 & 200 & 150 & 150 & 50 & 400 & 150 & & \\
\hline Llarch & 580 & .450 & 250 & 250 & 80 & & & & & & & \\
\hline Llecsia & 1,100 & .853 & 350 & 350 & 300 & 100 & & & & & & \\
\hline Martisella & 1,320 & 1.024 & 300 & 450 & 300 & 200 & 70 & & & & & \\
\hline Mas-Cortal & 3,200 & 2.482 & 600 & 1,000 & 150 & 150 & 200 & 400 & 100 & 150 & 450 & \\
\hline Mas-mereichs & 1,800 & 1.396 & 700 & 700 & 400 & & & & & & & \\
\hline Mandraga & 650 & .504 & 400 & 250 & & & & & & & & \\
\hline Mangaucha & 1,150 & .892 & 400 & 300 & 250 & 150 & 50 & & & & & \\
\hline Mariano & 1,000 & .776 & 350 & 300 & 300 & 50 & & & & & & \\
\hline Martí & 2,250 & 1.745 & 400 & 400 & 300 & 500 & 150 & 200 & 50 & 200 & 50 & \\
\hline Maistre & 1,300 & 1.008 & 500 & 400 & 400 & & & & & & & \\
\hline Mora & 1,624 & 1.260 & 200 & 250 & 210 & 64 & 550 & 250 & 100 & & & \\
\hline Mocho & 500 & .388 & 200 & 300 & & & & & & & & \\
\hline Molné & 1,850 & 1.435 & 450 & 500 & 400 & 200 & 300 & & & & & \\
\hline \multicolumn{13}{|l|}{ Molines } \\
\hline d'Andorra & 1,200 & .931 & 350 & 500 & 350 & & & & & & & \\
\hline Muyeró & 1,465 & 1.136 & 500 & 600 & 25 & 250 & 50 & 40 & & & & \\
\hline Mestrança & 480 & .372 & 250 & 230 & & & & & & & & \\
\hline Mijera & 250 & .194 & 250 & & & & & & & & & \\
\hline Naudi & 1,500 & 1.163 & 500 & 250 & 300 & 150 & 250 & 50 & & & & \\
\hline Pajó & 220 & .171 & 100 & 120 & & & & & & & & \\
\hline Panset & 250 & .194 & 250 & & & & & & & & & \\
\hline Pallisé & 2,785 & 2.160 & 410 & 310 & 300 & 200 & 310 & 305 & 300 & 100 & 350 & 200 \\
\hline Patjeta & 1,350 & 1.047 & 350 & 500 & 500 & & & & & & & \\
\hline Puncernal & 1,500 & 1.163 & 400 & 300 & 100 & 400 & 300 & & & & & \\
\hline
\end{tabular}


TABLE B2

(Continued)

\begin{tabular}{|c|c|c|c|c|c|c|c|c|c|c|c|c|}
\hline \multirow{2}{*}{$\frac{\text { FARM NAME }}{\text { Peret }}$} & \multirow{2}{*}{$\frac{\text { VALUATION }}{1,440}$} & \multirow{2}{*}{$\begin{array}{c}\text { Percent } \\
1.117\end{array}$} & \multirow{2}{*}{$\begin{array}{c}\text { House } \\
300\end{array}$} & \multirow{2}{*}{$\frac{\text { BARN }}{300}$} & \multicolumn{8}{|c|}{$\begin{array}{c}\text { Other Properties Insured } \\
\text { (Truncated at } 8 \text { ) }\end{array}$} \\
\hline & & & & & 280 & 120 & 40 & 150 & 50 & 100 & 100 & \\
\hline Peretol & 1,200 & .931 & 300 & 250 & 120 & 200 & 50 & 200 & 50 & 30 & & \\
\hline Popaire & 1,250 & .970 & 550 & 350 & 100 & 200 & 50 & & & & & \\
\hline Potablanch & 300 & .233 & 150 & 150 & & & & & & & & \\
\hline Ponet & 1,950 & 1.512 & 400 & 650 & 100 & 200 & 100 & 500 & & & & \\
\hline Piedro & 1,500 & 1.163 & 400 & 400 & 150 & 50 & 100 & 400 & & & & \\
\hline Pirot & 1,200 & .931 & 400 & 300 & 250 & 200 & 50 & & & & & \\
\hline Pep & 200 & .155 & 160 & 40 & & & & & & & & \\
\hline $\begin{array}{l}\text { Popblado } \\
\text { del Ros }\end{array}$ & 120 & .093 & 120 & & & & & & & & & \\
\hline Punchenta & 650 & .504 & 200 & 150 & 100 & 100 & 100 & & & & & \\
\hline Pincho & 300 & .233 & 300 & & & & & & & & & \\
\hline Parroco & 1,400 & 1.086 & 400 & 400 & 200 & 300 & 100 & & & & & \\
\hline Raji & 2,750 & 2.133 & 500 & 400 & 200 & 300 & 200 & 400 & 100 & 250 & 300 & 100 \\
\hline Rauquet & 1,524 & 1.182 & 400 & 350 & 24 & 200 & 50 & 50 & 100 & 50 & 150 & 150 \\
\hline Roigs & 2,600 & 2.017 & 400 & 500 & 500 & 900 & 300 & & & & & \\
\hline Roca & 700 & .543 & 700 & & & & & & & & & \\
\hline Ros & 200 & .155 & 200 & & & & & & & & & \\
\hline Rossell & 1,850 & 1.435 & 550 & 300 & 350 & 550 & 100 & & & & & \\
\hline Roca Ransol & 200 & .155 & 200 & & & & & & & & & \\
\hline Roch & 900 & .698 & 500 & 400 & & & & & & & & \\
\hline Rectora & 1,530 & 1.187 & 400 & 600 & 100 & 100 & 150 & 80 & 100 & & & \\
\hline Sucarana & 650 & .504 & 250 & 200 & 200 & & & & & & & \\
\hline Sinfreu & 1,261 & .978 & 400 & 45 & 400 & 350 & 16 & 50 & & & & \\
\hline Som & 1,700 & 1.319 & 400 & 300 & 50 & 150 & 500 & 150 & 150 & & & \\
\hline Soldevila & 2,200 & 1.706 & 600 & 500 & 200 & 300 & 50 & 300 & 200 & 50 & & \\
\hline Toni Canillo & 1,510 & 1.171 & 400 & 300 & 60 & 300 & 250 & 200 & & & & \\
\hline Toni Forn & 1,150 & .892 & 400 & 150 & 350 & 150 & 100 & & & & & \\
\hline Tomás & 1,300 & 1.008 & 450 & 850 & & & & & & & & \\
\hline Tarrado & 300 & .233 & 300 & & & & & & & & & \\
\hline Tristet & 980 & .760 & 200 & 80 & 350 & 350 & & & & & & \\
\hline Ton Burró & 1,350 & 1.047 & 350 & 500 & 500 & & & & & & & \\
\hline Vecaina & 1,000 & .776 & 250 & 250 & 380 & 120 & & & & & & \\
\hline Vidal & 1,480 & 1.148 & 300 & 400 & 80 & 60 & 20 & 250 & 200 & 70 & 50 & 50 \\
\hline Victorio & 750 & .582 & 200 & 150 & 200 & 200 & & & & & & \\
\hline Xigarró & 500 & .388 & 300 & 200 & & & & & & & & \\
\hline Xicos & 1,450 & 1.125 & 350 & 350 & 50 & 300 & 400 & & & & & \\
\hline Total & 128,928 & 100 & & & & & & & & & & \\
\hline
\end{tabular}

Source. - La Crema book, Benito Marquet Armengol, Cal Ton de Borró, Canillo.

\section{References}

Barsky, Robert B.; Juster, F. Thomas; Kimball, Miles S.; and Shapiro, Matthew D. "Preference Parameters and Behavioral Heterogeneity: An Experimental Approach in the Health and Retirement Study." Q.J.E. 112 (May 1997):537-79.

Bennett, Paul. "Mutuality at a Distance? Risk and Regulation in Marine Insurance Clubs." Environment and Planning A 32 (January 2000): 147-63.

Besley, Timothy; Coate, Stephen; and Loury, Glenn. "The Economics of Rotating Savings and Credit Associations." A.E.R. 83 (September 1993): 792-810.

—. "Rotating Savings and Credit Associations, Credit Markets and Efficiency." Rev. Econ. Studies 61 (October 1994): 701-19.

Billingsley, Patrick. Probability and Measure. New York: Wiley, 1979.

Brutails, Jean-Auguste. La Coutume d'Andorre. Paris: Leroux, 1904. 2d ed. Andorra la Vella: Casal i Vall, 1965. 
Cass, David; Chichilnisky, Graciela; and Wu, Ho-Mou. "Individual Risk and $\mathrm{Mu}-$ tual Insurance." Econometrica 64 (March 1996): 333-41.

Chou, Ray Y.; Engle, Robert F.; and Kane, Alex. "Measuring Risk Aversion from Excess Returns on a Stock Index.” J. Econometrics 52 (April/May 1992): 201-24.

Comas d'Argemir, Dolors, and Pujadas, Joan Josep. Andorra, un pais de frontera: Estudi etnogràfic dels canvis econòmics, socials i culturals. Barcelona: Alta Fulla, 1997.

Fafchamps, Marcel. "Risk Sharing and Quasi-Credit." J. Internat. Trade and Econ. Development 8 (September 1999): 257-78.

Gabriel, Paul E., and Marsden, James R. "An Examination of Market Efficiency in British Racetrack Betting." J.P.E. 98 (August 1990): 874-85.

Garber, Harry D. "Considerations in a Mutual Life Insurance Company Conversion.” In Financial Management of Life Insurance Companies, edited by J. David Cummins and Joan Lamm-Tenant. Norwell, Mass.: Kluwer Academic, 1993.

Gulley, O. David, and Scott, Frank A., Jr. "Lottery Effects on Pari-Mutuel Tax Revenues." Nat. Tax J. 42 (March 1989): 89-93.

Heimer, Carol Anne. Reactive Risk and Rational Action: Managing Moral Hazard in Insurance Contracts. Berkeley: Univ. California Press, 1985.

López Muntanya, Esteve; Peruga Guerrero, Joan; and Tudel Fillat, Carmen. L'Andorra del segle XIX: De la nova reforma a la revolució del 1881. Andorra la Vella: Conselleria d'Educació i Cultura, 1988.

Malinvaud, Edmond. "Markets for an Exchange Economy with Individual Risks." Econometrica 41 (May 1973): 383-410.

McCloskey, Donald N. "The Open Fields of England: Rent, Risk, and the Rate of Interest, 1300-1815." In Markets in History: Economic Studies of the Past, edited by David W. Galenson. Cambridge: Cambridge Univ. Press, 1989.

Szpiro, George G. "Measuring Risk Aversion: An Alternative Approach." Rev. Econ. and Statis. 68 (February 1986): 156-59.

Townsend, Robert M. The Medieval Village Economy: A Study of the Pareto Mapping in General Equilibrium Models. Princeton, N.J.: Princeton Univ. Press, 1993.

Williams, C. Arthur, Jr.; Smith, Michael L.; and Young, Peter C. Risk Management and Insurance. Boston: Irwin McGraw Hill, 1997.

Young, H. Peyton. Individual Strategy and Social Structure: An Evolutionary Theory of Institutions. Princeton, N.J.: Princeton Univ. Press, 1998. 